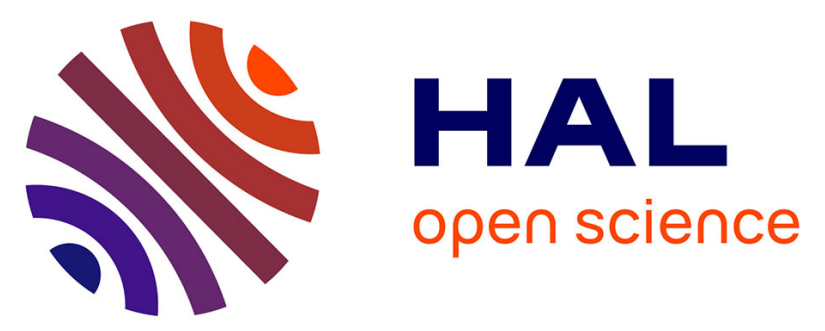

\title{
Cross-scale effects of structural and functional connectivity in pond networks on amphibian distribution in agricultural landscapes
}

Alienor Jeliazkov, Romain Lorrillière, Aurélien Besnard, Josette Garnier, Marie Silvestre, François Chiron

\section{To cite this version:}

Alienor Jeliazkov, Romain Lorrillière, Aurélien Besnard, Josette Garnier, Marie Silvestre, et al.. Crossscale effects of structural and functional connectivity in pond networks on amphibian distribution in agricultural landscapes. Freshwater Biology, 2019, 64 (5), pp.997-1014. 10.1111/fwb.13281 . hal02139448

\section{HAL Id: hal-02139448 \\ https://hal.sorbonne-universite.fr/hal-02139448}

Submitted on 24 May 2019

HAL is a multi-disciplinary open access archive for the deposit and dissemination of scientific research documents, whether they are published or not. The documents may come from teaching and research institutions in France or abroad, or from public or private research centers.
L'archive ouverte pluridisciplinaire HAL, est destinée au dépôt et à la diffusion de documents scientifiques de niveau recherche, publiés ou non, émanant des établissements d'enseignement et de recherche français ou étrangers, des laboratoires publics ou privés. 


\title{
Cross-scale effects of structural and functional connectivity in pond networks on amphibian distribution in agricultural landscapes
}

\author{
Alienor Jeliazkov $^{1,2}$ (D) | Romain Lorrillière ${ }^{3,4}$ (D) $\mid$ Aurélien Besnard $^{5}$ (D) | \\ Josette Garnier $^{6}$ (D) | Marie Silvestre ${ }^{7}$ (D) | François Chiron ${ }^{4}$ (iD
}

${ }^{1}$ German Centre for Integrative Biodiversity Research (iDiv) Leipzig-Halle-Jena, Leipzig, Germany

${ }^{2}$ Department of Conservation Biology, UFZ

- Helmholtz Centre for Environmental

Research, Leipzig, Germany

${ }^{3}$ CEFE UMR 5175, Biogéographie et Ecologie des Vertébrés, PSL Research University, EPHE, CNRS, Université de Montpellier, Université Paul-Valéry

Montpellier, Montpellier, France

${ }^{4}$ UMR 8079, Ecologie, Systématique et Evolution, CNRS, AgroParisTech, University of Paris-Sud, Université Paris Saclay, France

${ }^{5} \mathrm{EPHE}, \mathrm{PSL}$ Research University, CNRS, UM, SupAgro, IRD, INRA, UMR 5175 CEFE, F-34293 Montpellier, France 2 CREA, Chamonix Mont-Blanc, France

'UPMC \& CNRS, UMR 7619, Laboratoire

Metis, Université Pierre et Marie

Curie, Paris, France

${ }^{7}$ Sorbonne Université, CNRS, Fédération Ilede-France de Recherche en Environnement, FR3020 FIRE, Paris, France

\section{Correspondence}

Alienor Jeliazkov, German Centre for Integrative Biodiversity Research (iDiv) Leipzig-Halle-Jena, Leipzig, Germany.

Email: alienor.jeliazkov@gmail.com

\begin{abstract}
1. Connectivity in pond ecosystems is essential for amphibian population persistence. To test the role of connectivity, a diversity of scales accounting for the different processes underlying species distribution needs to be considered. Several approaches exist for accounting for the potential connectivity, mainly based on structural versus functional methods. Based on occupancy data, our aim was to assess the relative power of connectivity metrics in explaining amphibian distribution when accounting for cross-scale effects from pond to network scales, and to identify network features relevant to amphibian conservation in agricultural landscapes in the Seine-et-Marne department (east of Paris, France).
\end{abstract}

2. We propose an original analytical framework that allows examining different spatial scales of influence, with a focus on connectivity. We analyse the distribution of three amphibian species (Bufo bufo, Rana dalmatina, and Lissotriton vulgaris) in relation to various pond conditions (fish presence, water quality, and nearby woodland habitat) as well as connectivity using three connectivity approaches: (1) structural, (2) area-functional based on potential migration areas, and (3) path-functional based on the least accumulated cost paths. Values of landscape resistance were assigned according to a biological risk-based approach that is proposed as an enhanced, transparent expert-based approach. We further investigated cross-scale effects in amphibian responses to the environment by assessing the relative importance of pond and network characteristics as well as their interactions.

3. Despite some species-specific characteristics, the area-functional approach of connectivity was generally the most effective in explaining species distribution by emphasising the relevance of potential migration areas as conservation units. Although pond conditions usually had a greater influence than network connectivity, we highlighted important cross-scale and threshold effects in species' response to local conditions, to pond connectivity, and to the availability of potentially suitable terrestrial habitats in the networks.

4. Our cross-scale approach accounts for scale-dependent processes that potentially underlie amphibian distribution such as habitat selection and metapopulation 
dynamics. Both structural and functional connectivity should be considered as complementary features of pond connectivity when dispersal traits are likely to be less limiting. From a management perspective, our results encourage conservation plans to combine functional network-centred strategies with the preservation of local conditions. We give guidelines as to the features of such networks to help maintain amphibian populations in agricultural landscapes.

\section{KEYWORDS}

agricultural areas, amphibian conservation, landscape connectivity, pond networks, scales

\section{1 | INTRODUCTION}

One of the main challenges in biodiversity research is better predicting species distribution in the face of unprecedented environmental changes and habitat loss. Improving our models requires going beyond the simple habitat models (Guisan \& Thuiller, 2005) and explicitly integrating ecological connectivity, as this is a crucial aspect of population persistence in the landscape (Bennett, 2003; Hilty, Lidicker, Merenlender, \& Dobson, 2006).

Understanding the role of connectivity in species distribution is essential, but it remains a challenging task because it requires encompassing the diversity of scales at which processes shape species distribution (Levin, 1992; Noss, 1991). Environmental control, metapopulation dynamics, and seasonal migration are all key processes with different and, sometimes, interacting operating scales. Moreover, connectivity can be characterised and modelled according to various paradigms (Calabrese \& Fagan, 2004; Fischer \& Lindenmayer, 2007). Landscape connectivity sensu lato was defined as "the degree to which the landscape facilitates or impedes individual movement between resource patches" (Taylor, Fahrig, Henein, \& Merriam, 1993), with certain differences between structural and functional connectivity (Tischendorf \& Fahrig, 2000; Uezu, Metzger, \& Vielliard, 2005). Structural connectivity refers to the physical structure of the landscape (i.e. shape, number of resource patches, and distance between them) and can be independent of any trait of the organism of interest. On the contrary, functional connectivity accounts for the ecological traits of the organism (Tischendorf \& Fahrig, 2000): maximum distance of dispersal, energetic cost of displacement across different types of land covers, mortality risks associated with crossing hostile habitats, etc. Based on speciesspecific characteristics, functional connectivity often appears as a better proxy of actual ecological connectivity between habitats that results from biological processes (Fischer \& Lindenmayer, 2007).

In the present study, we focus on amphibians in pond ecosystems. Several studies have demonstrated the importance of pond connectivity for species and population persistence (e.g. Fortuna, Gomez-Rodriguez, \& Bascompte, 2006; Ribeiro et al., 2011). As ground-dwelling animals with inter-seasonal mobility, due to the biphasic life cycle of some species (i.e. aquatic and terrestrial), amphibians are dependent on both pond conditions and habitat connectivity.
In addition, some amphibians function according to metapopulation dynamics and have strong breeding site fidelity (e.g. Smith \& Green, 2005) and high species turnover (e.g. Trenham, Koenig, Mossman, Stark, \& Jagger, 2003). These traits indicate that amphibian populations can be sensitive to both local and regional environmental conditions (Skelly, 2013; Werner, Yurewicz, Skelly, \& Relyea, 2007) and to the spatial configuration of the ponds (Cushman, 2006).

There have been different ways to account for connectivity when studying amphibian distribution. Pond connectivity is often estimated through buffer approaches by calculating metrics such as the number of ponds, or the presence of barriers in circular zones around a focal pond (Pellet, Hoehn, \& Perrin, 2004; Simon, Snodgrass, Casey, \& Sparling, 2008; Zanini, Klingemann, Schlaepfer, \& Schmidt, 2008). Based on this approach, Prugh (2009) showed that the number of adjacent occupied habitats, as potential sources of propagules, better predicts amphibian occupancy and colonisation than the simple number of suitable habitats. Some studies also assessed species distribution according to network-centred approaches. A network is considered as a group of inter-dependent ponds that can be related to each other via spatial and temporal processes, and exchanges of information. The explicit description of pond network connectivity can be either structural (Fortuna et al., 2006; Ribeiro et al., 2011) or functional (Joly, Morand, \& Cohas, 2003; Ray, Lehmann, \& Joly, 2002). Comparing network-centred and buffer approaches, Ray et al. (2002) showed that the functional network approach performed better than the structural buffer approach in predicting amphibian occurrence. The former takes into account the energy costs associated with movement through particular types of habitats and, thus, the area and shape of potential migration zones, whereas the latter assumes a circular and homogeneously permeable migration zone. However, these comparative analyses do not take into account the local condition effects, although some studies have demonstrated the additive effects of pond characteristics and network variables (Decout, Manel, Miaud, \& Luque, 2012; Ribeiro et al., 2011), especially using valuable advances based on graph theory (Clauzel, Girardet, \& Foltête, 2013).

Another important aspect to consider when investigating the potential processes underlying a species' distribution, which is subject to different scales of influence, is the cross-scale interactions. The idea of cross-scale interactions (Peters, Bestelmeyer, \& Turner, 2007; 
Schneider, 2001) is a consequence of the hierarchy theory (Allen \& Starr, 1982). A relationship at one given level (whether spatial, temporal, or organisational) can be constrained by the characteristics of the upper level and can gain new properties from the combination of lower-level characteristics (O'Neill, Johnson, \& King, 1989). In particular, processes operating at different spatial scales can interact with each other and generate particular biological patterns on a given scale (Lawler \& Edwards, 2006). Analysing cross-scale interactions thus allows one to link patterns emerging at different scales and to relate these patterns to potential processes (Peters et al., 2007) (see an illustration of cross-scale interactions in Supporting Information Appendix S1).

Some studies investigated the interaction between pond- and landscape-level effects on amphibians, as the alteration of local conditions could, for instance, limit the positive effect of connectivity by impeding the settlement of colonisers (Joly et al., 2003). Complex interactions between local habitat selection (e.g. for reproduction, growth), seasonal migration through the landscape, and metapopulation processes (dispersal) were shown to have important effects on both species distribution and community patterns (Ficetola, Marziali, Rossaro, Bernardi, \& Padoa-Schioppa, 2011; Werner et al., 2014). Several studies have investigated the additive (e.g. Denoël \& Ficetola, 2008) and interactive effects (Ficetola et al., 2011; Guerry $\&$ Hunter, 2002) of pond and landscape variables on amphibian populations. However, no framework has been available yet to investigate the interaction effects (cross-scale effects) between pond local conditions and functional and structural connectivity at pond and network scales together in a single study.

We propose here a hierarchical analytical framework based on a nested structure with three spatial scale levels (Schaldach et al., 2011), later on referred as to scales: pond, pond in network, and network. This nested structure is used to build the predictors of species distribution and approaches different scales of influence, while the response scale is fixed; the pond scale. This original approach allows us to describe the habitat and connectivity features, and to test their relation with species distribution, as well as all their within-scale and cross-scale interactions (Peters et al., 2007).

In an agricultural zone, we estimated the occurrence probability of three amphibian species (Bufo bufo, Rana dalmatina, and Lissotriton vulgaris), which have different habitat requirements, distributional patterns, and dispersal abilities. (1) We tested the link between amphibian distribution, and structural and functional connectivity metrics to assess their relative influence. (2) We assessed the scaledependence and cross-scale effects of the environment on amphibian distribution. (3) For every species, we identified networks that could be considered as relevant management units and ranked their connectivity features in order of importance, which would consequently constitute action targets with regard to amphibian conservation in an agricultural landscape.

Our working hypotheses are as follows:

(1a) Generally, functional measures of network connectivity are expected to explain amphibian species distribution better than structural ones because the former take into account the species' perception of the landscape, the availability of potential sources of resources, shelters (e.g. for hibernation; Neill, 1948), and the biological risks involved in migration/dispersal processes (e.g. Janin, Léna, Deblois, \& Joly, 2012). (1b) Assuming that amphibian population can benefit from the nearby presence of potential sources of propagules, we generally expect a positive effect of pond connectivity to any network (e.g. pond centrality) on the species' probability of occurrence. (1c) As a corollary, we expect network expansion, and network resistance to have negative effects, by making the potential sources further apart, and by altering the connectivity between these sources, respectively.

(2) We already showed the importance of local conditions (i.e. fish presence, water quality, and neighbouring proportion of woodland cover) for these specific species in this study area (Jeliazkov et al., 2014). We here focus on the relative importance of network and pond-in-network characteristics in addition to, and in interaction with local conditions. We expected that the influences from the pond, pond-in-network, and network scales could interact by amplifying or suppressing each other. (2a) We expect local conditions to interact with connectivity: e.g. a pond with poor local conditions, even if well connected, will not allow the species to settle (Joly et al., 2003). (2b) We also expect the network-scale variables to interact with each other; e.g. the spatial expansion of the network could have a positive effect in the case of low network resistance, because this would provide a higher number of available and reachable ponds but this effect could become negative if the resistance is too high.

(3) Because of species-specific dispersal abilities, we expect contrasting responses depending on the species, with the best dispersers being less limited by connectivity compared to poor dispersers. We expect different thresholds to exist for the species' responses to network variables. In landscapes where the suitable habitats are initially scarce and fragmented, the positive relationships with connectivity metrics may only be detected for the highest values of habitat availability or accessibility (Metzger \& Décamps, 1997).

\section{METHODS}

\section{1 | Study area and pond survey}

The study area $\left(c .430 \mathrm{~km}^{2}\right.$ ) is located in the French Seine-et-Marne department (eastern Ile-de-France region; $48.6^{\circ} \mathrm{N} / 3.2^{\circ} \mathrm{E}$ ). This site is representative of an intensive agricultural landscape, with $80 \%$ of the area covered by cereal crops.

In this study area, we located ponds based on the French national BD TOPO ${ }^{\circledR}$ v2 (IGN, 2008) and two complementary regional pond censuses (2009-2012) (Département de Seine-et-Marne \& SNPN, 2012) (spatial precision $5 \mathrm{~m}$ ).

We selected 160 out of 300 ponds in the study area on the basis of two criteria. First, we selected permanent ponds to avoid major differences in ecological functioning, which is linked to the hydrological regime. Second, we chose ponds within clusters of different 
pond densities in which inter-pond distances did not exceed 2,000 $\mathrm{m}$. This distance allowed us to: (1) to remain in the range of the known maximum migration distances of most of the amphibian species under study (Jeliazkov et al., 2014); and (2) have a sufficient number of distinct clusters for analyses $(n=15)$, and a reasonable gradient of cluster densities, i.e. number of ponds per cluster $(n \in\{1,2,3,4,5,6$, $7,12,13,20,27,50\})$. These clusters are not the networks themselves but were used as initial patterns to guide the sampling. Very few interstitial ponds were missed or unsampled in our area. We omitted temporary ponds as well as those destroyed during the survey. We acknowledge that temporary ponds potentially act as important stepping stone habitats for some species and their presence could influence the analysis of amphibian distribution. In our case, however, most of the ponds were historically artificial, and there were no temporary ponds within the sampling clusters (BD TOPO ${ }^{\circledR} v 2$ IGN, 2008) and potentially only very few in the vicinity of clusters (Département de Seine-et-Marne \& SNPN, 2012; Jeliazkov, 2013). Thus, their effect is probably negligible compared to the effects we investigated.

We assessed the occurrence of three amphibian species-B. bufo, R. dalmatina, L. vulgaris-at the 160 sites in 2011 and 2012 using a standardised protocol (52 ponds in 2011, 65 in 2012, and 35 in both years). Since there was no substantial year effect in the speciesoccurrence data (Jeliazkov et al., 2014), we merged the data of the two annual campaigns into a single visit dataset for the analyses (Chase \& Ryberg, 2004).

We conducted two fortnight nocturnal sessions per year during the main reproductive seasons (March and June). We combined three complementary methods to detect, identify, and count individuals of the target taxa at different stages, while minimising habitat destruction: records of calling males, observations using lamps along the pond banks, and dip-netting. See Jeliazkov et al. (2014) for more details.

We also recorded the presence/absence of potentially predatory fish based on visual observations, dip-netting, and/or information provided by pond owners.

Furthermore, the physical-chemical characteristics of the water were measured four times (twice per year): dissolved oxygen, water temperature, $\mathrm{pH}$, concentrations of ammonium, ammonia, nitrates, nitrites, silica, phosphates, and chlorophyll a (see Jeliazkov et al., 2014). Based on these parameters, we calculated an average water quality index (WQI) ranging from $0 \%$ (very poor quality) to $100 \%$ (very good quality). The WQI was adapted from (Pesce \& Wunderlin, 2000; Sánchez et al., 2007) as it has proven to be a good indicator of water quality with regard to amphibian response. The availability of terrestrial habitats around the ponds was represented by the proportion of wood cover within a 200-m-radius buffer zone surrounding the ponds (for more information on the methods, see Jeliazkov et al., 2014). These variables were used as pond-scale predictors of amphibian occurrence (see next sections).

\section{2 | Study species}

We studied two anuran and one urodele species that have different habitat requirements, distributional patterns, migration behaviours, and dispersal abilities (for a literature-based synthesis, Supporting Information Appendix S2). The three species have the following general sequence of seasonal events in common; prenuptial migration of the adults from summering sites to the breeding pond; reproduction in the breeding pond; egg-laying followed by the development of tadpoles/larvae; postnuptial migration of adults to the wintering sites; dispersal of juveniles; and wintering period. However, they have different phenology and use different types of habitat to complete these stages.

Bufo bufo-the common toad-generally prefers cool, wet, nutrientrich and wooded environments (ACEMAV coll., 2003) but it can be found in a variety of habitats (Arnold \& Ovenden, 2014). The wintering sites are generally close to the breeding site ( $<500 \mathrm{~m}$, up to $1,000 \mathrm{~m}$; ACEMAV coll., 2003). After hibernation, the adults massively migrate to the reproduction zone that is often-but not necessarily-the same as the previous year (Reading, Loman, \& Madsen, 2009). The reproduction results in c. 3,000-8,000 eggs per female per season. In summer, juveniles leave the water and shelter in ground cracks, or under the vegetation around the pond shore before being able to disperse across terrestrial habitats. After reproduction, the adults migrate to summering sites up to $1,000 \mathrm{~m}$ away from the breeding site (Sztatecsny \& Schabetsberger, 2005) but can travel up to $3 \mathrm{~km}$ (Smith \& Green, 2005; Supporting Information Appendix S2). They have few predators (snakes, herons, otters) and specific defence mechanisms against predation from fish (Gunzburger \& Travis, 2005; Kats, Petranka, \& Sih, 1988).

Rana dalmatina-the agile frog-prefers woodland habitats, especially dense deciduous forest, although it can also be found in woodlots and some grasslands. It can stay in dry areas outside the reproduction season (Arnold \& Ovenden, 2014). It coexists with other amphibian species but usually avoids fishponds. In summer, the adults have distinct vital ranges of about tens of meters square in wooded or grassland areas. The distance between the vital range and the reproduction site reaches $1 \mathrm{~km}$ (ACEMAV coll., 2003). The reproduction period is usually short and results in 450-1,800 eggs per female per season. Rana dalmatina migrates to terrestrial habitat in autumn and hibernates in the ground close to the reproduction site (Supporting Information Appendix S2).

Lissotriton vulgaris-the smooth newt-thrives in open habitats (Denoël \& Ficetola, 2007) such as agricultural areas, gardens, and field edges, but there is no real consensus about its actual relation to woodlands, whether positive or negative (Denoël, Perez, Cornet, \& Ficetola, 2013; Supporting Information Appendix S2). It may have a high fidelity to the reproduction site (Smith \& Green, 2005). It prefers small and shallow ponds with vegetation and ditches. The reproduction season can end with a postnuptial migration or with a longer stay in the water, sometimes until December (ACEMAV coll., 2003). The egg-laying is much less productive than the two other species with c. 200-300 eggs per female per season. The hibernation of the adults usually takes place in the ground.

\subsection{Definition of structural and functional networks}

To accurately characterise the habitat connectivity between the sampled ponds and delimit the networks, we combined three geographic 
information system (GIS) regional databases: MOS (IAU IDF, 2008) providing detailed information about urban infrastructures and arable land, Ecomos (IAU IDF, 2005) focusing on semi-natural areas such as forest and grassland, and Ecoline (IAU IDF, 2012) surveying all semi-natural features of the landscape such as single trees, hedgerows, groves, and field margins at a very fine spatial resolution $(1: 2,500)$ and precision $(20 \mathrm{~cm})$ (Supporting Information Appendix S3).

To create network maps, we first converted all the vector layers to raster format with a $3 \times 3 \mathrm{~m}$ pixel resolution and then merged them to a single raster layer referred to as landscape (Supporting Information Appendix S4). The grain size used for connectivity analyses needs to be appropriately chosen (Baguette \& Van Dyck, 2007; Galpern \& Manseau, 2013). In our case, the grain of $3 \times 3 \mathrm{~m}$ was a good compromise between the species' perception abilities (Rothermel, 2004) and the high precision level (both in spatial and thematic resolutions) provided by the landscape database Ecoline, thus allowing a maximum amount of valuable information to be conserved.

All GIS treatments, including generating the networks, were performed with ArcGIS for Desktop9.3/9.4 ${ }^{\circledR}$ (under Basic license, formerly ArcView), Spatial Analyst, and ETGeoWizard10 ${ }^{\circledR}$.

To assess the resistance of the landscape features, we attributed resistance coefficients to the main cover types based on previous studies dealing with the same three amphibian species. Following an extensive literature search focussing precisely on the three species under study, we identified 10 studies that provided direct, indirect, or expert estimates. Values for mainland covers such as woodlands, crops, grasslands, urban areas, and roads were taken from the following references: Cushman, Compton, \& McGarigal, 2010; Decout et al., 2012; Janin et al., 2009; Joly et al., 2003; Lenhardt, Schäfer, Theissinger, \& Brühl, 2013; Patrick, Gibbs, Popescu, \& Nelson, 2012; Ray et al., 2002; Van Buskirk, 2012; Vos, Goedhart, Lammertsma, \& Spitzen-Van der Sluijs, 2007; Zetterberg, Mörtberg, \& Balfors, 2010. Note that Van Buskirk (2012) was only used to inform the relative resistance of the different habitat types as it provided measures that were not directly comparable to ours. Because urodeles have usually proved to be worse migrators than anurans (e.g. Semlitsch \& Bodie, 1998; Smith \& Green, 2005), we amplified the resistance values of unfavourable habitats for the newt species (Ray et al., 2002). Although we found resistance values for most areal elements, there was no information for the fine elements censed in Ecoline except for hedgerows (Lenhardt et al., 2013). Thus, based on a thorough reasoning about the potential biological risks of the species crossing various habitats, we classified these elements according to the cover structure (strata height and density), hierarchised the associated biological risks (i.e. predation, desiccation, poisoning, physical barrier, and direct mortality), and attributed a value of resistance accordingly (Table 1).

The landscape raster was then reclassified into a cost raster using resistance values. The higher the probability for a species to migrate through a cell, the lower the cost.
Using the cost distance algorithm from ArcGIS Spatial Analyst, we built a map of the least accumulated costs (weighted distances) from any pixel of our study area to the nearest pond. This allowed us to define potential migration areas (PMA) around the ponds that formed functional networks when merged together according to a set of species-specific maximal migration distances (MMD; see the next section). Then, to compute the least-cost paths between prospected ponds, we used the cost path algorithm and recorded the length and mean accumulated cost of the paths (Supporting Information Appendix S4).

\subsection{Analytical framework for comparing effects of structural and functional connectivity and assessing cross-scale effects}

The structural and functional approaches were all constrained by the same set of species-specific MMD (ACEMAV coll., 2003; Semlitsch \& Bodie, 2003; Smith \& Green, 2005):

- $1,000,1,500$, and $2,000 \mathrm{~m}$ for B. bufo;

- 300, 500, and 1,000 m for R. dalmatina;

- 100,200 , and $800 \mathrm{~m}$ for L. vulgaris.

We used three different approaches to build networks and measure pond connectivity:

1. The structural approach (S) refers to potential pond connectivity (Calabrese \& Fagan, 2004) and was based on inter-pond Euclidean distances in the limit of the MMD (Figure 1a).

2. The area-functional approach (AF) was based on the merging of the PMAs around the ponds resulting from the mapping of the landscape resistance (Figure $1 \mathrm{~b}$ ). PMAs are proxies of habitat connectivity for migration between ponds by adult individuals (Ray et al., 2002) and/or for dispersal. They also reflect habitat availability and quality around ponds, including potential sources of resources (e.g. Janin, Léna, \& Joly, 2011) and shelters.

3. The path-functional approach (PF) involved considering the physiological constraint of cost accumulation along the least-cost paths that linked the ponds to each other from among all the possible distances in the limit of the MMD (Figure 1c). In this case, a dispersing animal accumulates costs during its displacement in relation to potential biological risks encountered over the distance travelled in the limit of the MMD (e.g. Bartelt, Klaver, \& Porter, 2010). In some cases, the path-functional networks can appear less limited than the area-functional ones in terms of the number of connected ponds, but this implies a unique path and a directional inter-pond movement. As the accumulated cost measures have been shown to be more realistic than the least-cost path measures for assessing habitat connectivity (Etherington \& Holland, 2013), the path-functional measure of network connectivity was expected to better explain the species distribution compared to the structural measure and to be complementary with the area-functional measure. 


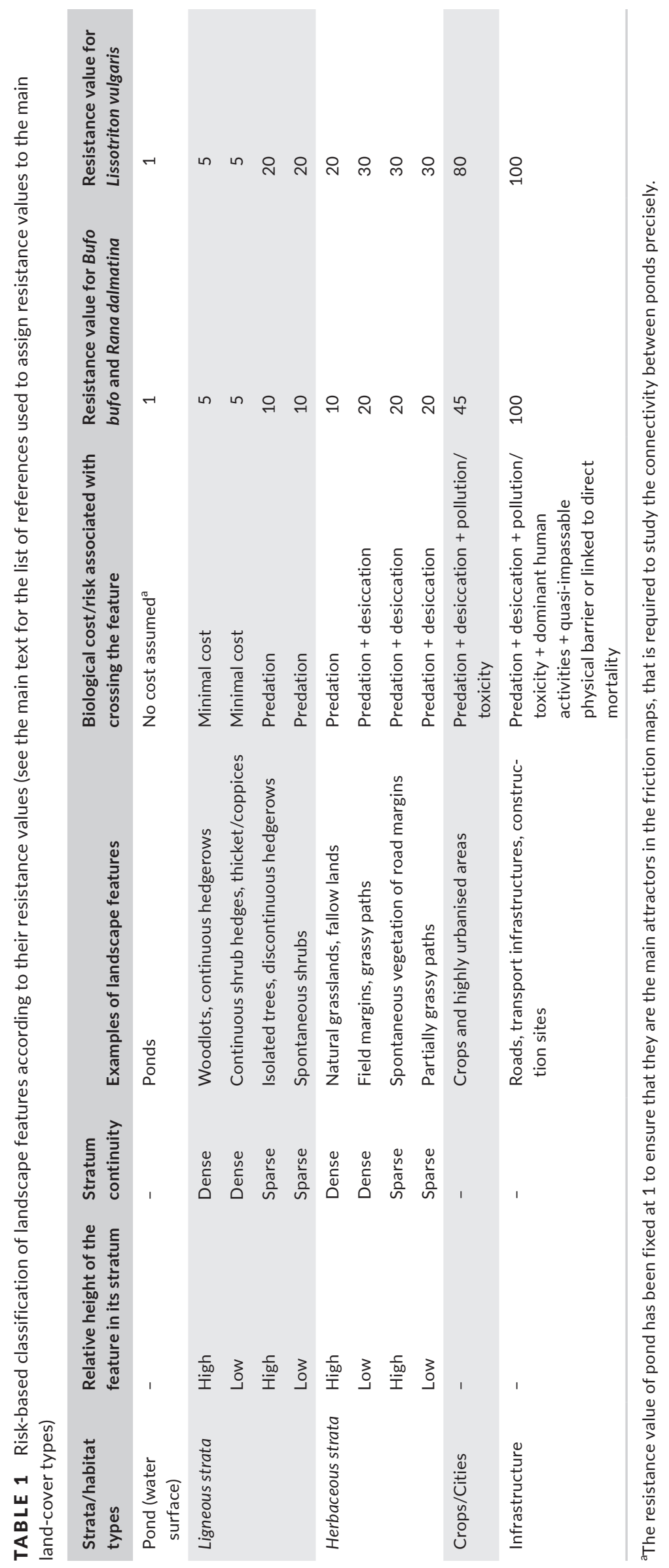


(a)

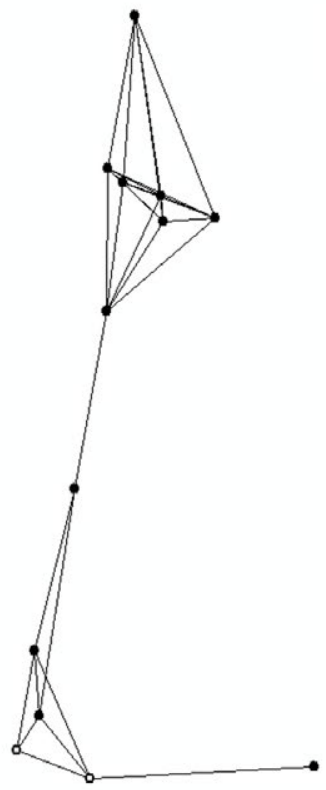

- Ponds with B. bufo

- Ponds without B. bufo

Structural links between (b)

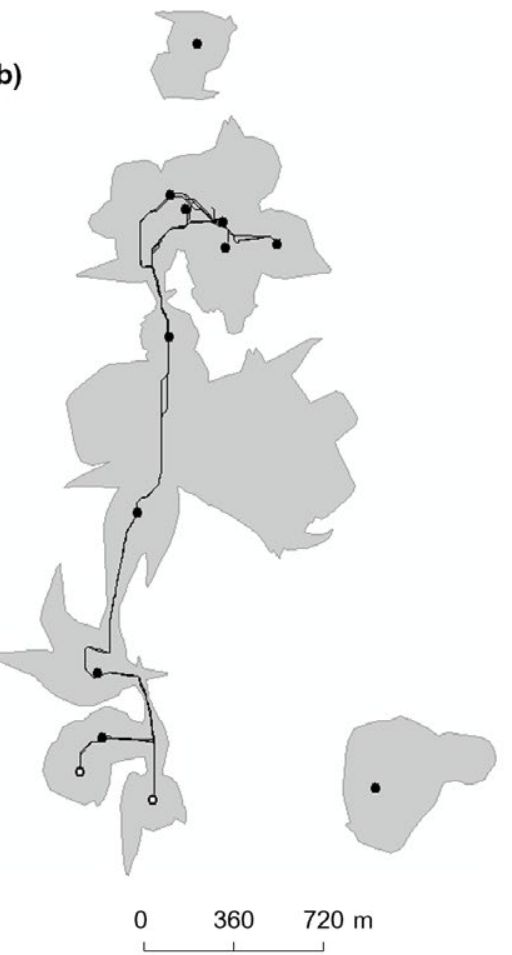

Potential migration areas (MMD 1,000 m)

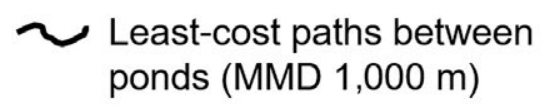

(c)

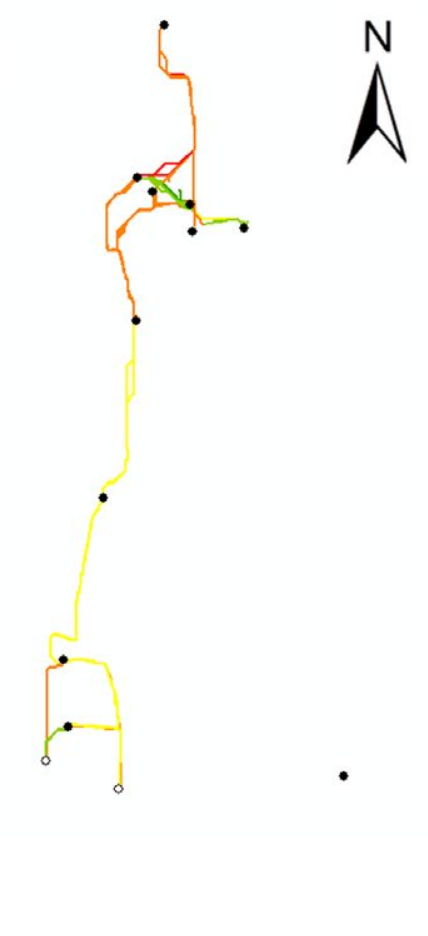

Mean accumulated-cost along the least-cost paths (MMD 1,000 m) 195,51-1049,57 $1049,57-4833,49$ 4833,49-10464 $10464-13045,4$ $13045,4-16404,4$

FIGURE 1 Example of a pond network under the three different connectivity approaches: (a) structural, (b) area-functional, and (c) path-functional, for Bufo bufo and a maximal migration distance (MMD) of 1,000 m. Mean accumulated cost values are weighted distances based on the resistance values of the different types of habitats crossed by the least-cost path and on the pixel resolution ( $3 \times 3 \mathrm{~m}$ ). The cost unit is metre-equivalent, e.g. to reach one pixel of woodland (of resistance value $=5$ ) through a straight line (length $=3 \mathrm{~m}$ ), the cost equals $5 \times 3 \mathrm{~m}=15$ metre-equivalent

We thus represented influences deriving from three scales: pond, pond-in-network, and network scales. We considered the following eight variables as potential predictors of amphibian occurrence probability: fish presence, water quality, proportion of woodland in the direct surrounding of the pond, distance to the nearest occupied pond, pond degree centrality (according to the three different connectivity approaches S, AF, and PF), network expansion (based on S), network resistance (based on AF), and network cumulated cost (based on PF) (see details in Table 2).

\section{5 | Statistical analyses}

The objectives of the analyses were to assess: (1) the relative importance of the variables from the different spatial scales; pond, pond-in-network, and network, and in particular, of the different structural, and functional connectivity metrics; (2) the interactions between the variables from the different scales; and (3) the potential thresholds with regard to species distribution. To do so, we modelled the occurrence of the three species in response to all variables of the different scales of influence under the three MMDs (thus, one model per species per MMD = nine models).

For all models, we first checked for multicollinearity within our set of explanatory variables. The three variables of degree centrality (PondCentral_S/AF/PF) were collinear. To ensure the comparability between models while solving the problem of collinearity, we kept the degree centrality calculated using the area-functional approach and excluded the two other measures in all models (Supporting Information Appendix S5a).

To analyse the relative and interactive effects of pond-, pondin-network-, and network-level variables on species distribution, we used the boosted regression tree method (De'ath, 2007) (package \{dismo\} in R Hijmans, Phillips, Leathwick, \& Elith, 2016) (Supporting 
TAB LE 2 Description of the pond-, pond-in-network-, and network-scale variables of which the main and interaction effects were tested for species occurrence. S, AF, and PF respectively refer to the structural, area-functional, and path-functional approaches of connectivity

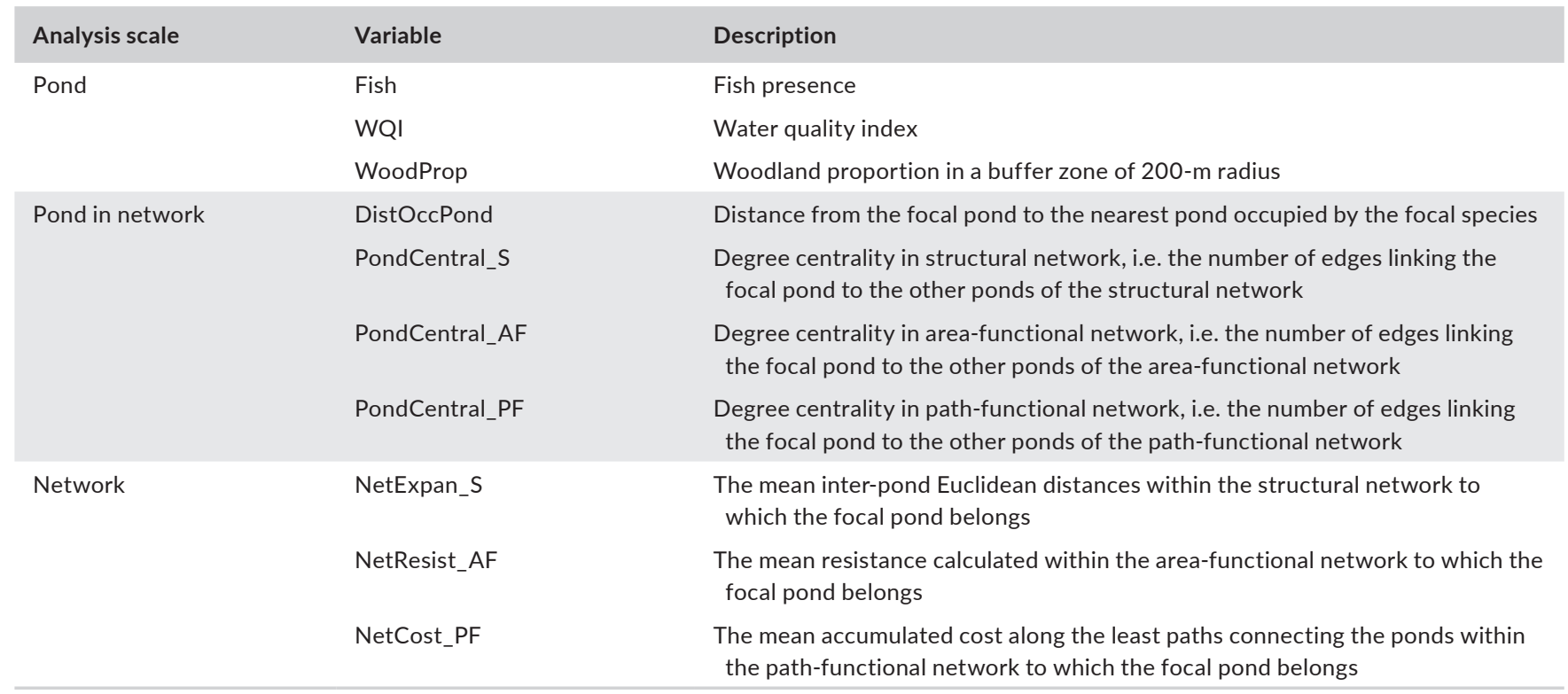

Information Appendix S5b). We modelled the residual distribution using the logit link function for binary responses. To obtain a reasonable number of trees $(>1,000)$ and good convergence (see Elith, Leathwick, \& Hastie, 2008), we used a bag fraction of 0.5 and a learning rate of 0.001 for all models.

We assessed the explanatory power of the final models using the pseudo- $R^{2}$ calculated as (TotalDeviance - ResidualDeviance)/ TotalDeviance.

To ensure model parsimony, we performed model simplification and estimated the percentage of deviance explained by each variable from the total deviance of the model. This allowed us (a) to rank variables according to the relative strength of their association with the species occurrence probability. We also (b) tested and selected all pairwise interactions for their relative importance (according to the residual variance generated by the linear model). As the boosted regression tree supports non-linear relationships, a graphical visualisation of the estimated species' response across scales allowed us (c) to identify potential thresholds.

All statistical analyses were performed with the statistical program R 3.3.1 (R Core Team, 2016).

\section{3 | RESULTS}

\section{1 | Species distribution and network description}

Species occurrence and PMAs are illustrated in Figure 2. In general, the network number varied from eight to 39 depending on the species, migration distance, and network type (i.e. structural, area-functional, and path-functional). A substantial number of ponds turned out to be isolated, especially in the case of the areafunctional network, which was generally amplified as the MMD decreased (Supporting Information Appendix S6).

\subsection{Effects of functional versus structural network connectivity measures on species occurrence}

When focussing on the network scale variables, all three connectivity metrics were predictive of species occurrence. However, the functional measures of network connectivity better explained species occurrence than the structural measure. The mean resistance within the area-functional network better explained the occurrence of R. dalmatina and L. vulgaris (Figure 3b,c), whereas the mean accumulated cost within the path-functional network better explained the occurrence of B. bufo (Figure 3a).

The probability of occurrence of both B. bufo and R. dalmatina showed a negative relationship with the network-scale variables (Figure $4 a, b$ ). In particular, the thresholds in the fitted function of occurrence probability in response to the network expansion indicated that the response to the mean network expansion became critical from the values of $600 \mathrm{~m}$, and $100 \mathrm{~m}$ for B. bufo, and R. dalmatina, respectively. Both species' occurrence probability also responded negatively to the mean network resistance, with a critical threshold value of average resistance at $30 \%$ (Figure 4a,b). By contrast, L. vulgaris' occurrence showed a positive relationship with the mean network resistance from a threshold value of 50\% (Figure 4c). However, these thresholds substantially varied depending on the MMD (Supporting Information Appendix S7).

\section{3 | Scale-dependence and cross-scale effects of pond and network variables}

On average, the pond variables explained a slightly higher deviance than the network variables in the cases of R. dalmatina and L. vulgaris, whereas pond and network variables were equally ranked in the case of B. bufo (Figure 3). However, this pattern largely depended on the 
(a)

- Ponds with $B$. bufo

- Ponds without B. bufo

Potential migration areas according to three maximum migration distances:

MMD 1,000 m

MMD 1,500 m

MMD 2,000 m

(b)

- Ponds with R. dalmatina

- Ponds without $R$. dalmatina

Potential migration areas according to three maximum migration distances:

MMD $300 \mathrm{~m}$

MMD $500 \mathrm{~m}$

MMD 1,000 m

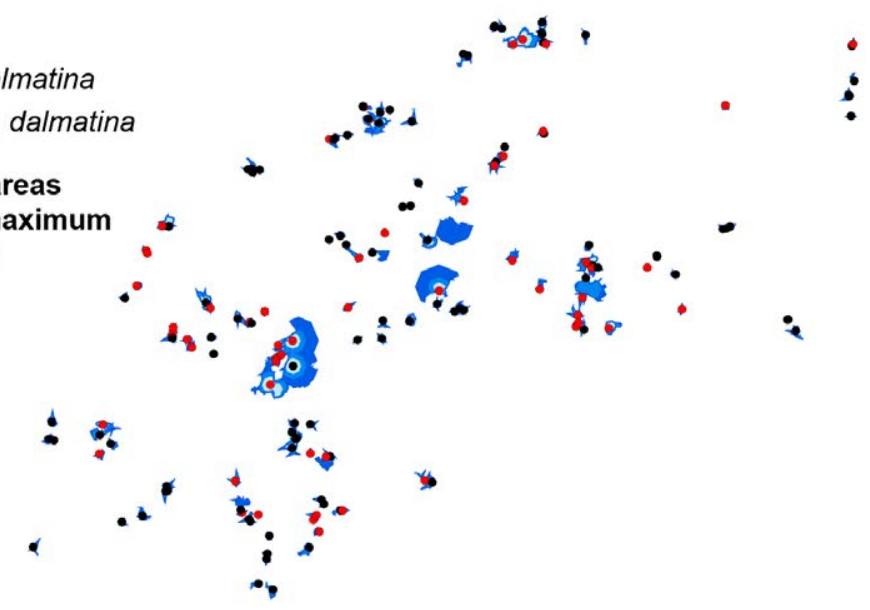

(c)

- Ponds with L. vulgaris

- Ponds without L. vulgaris

Potential migration areas according to three maximum migration distances:

FIGURE 2 Potential migration areas obtained from the resistance map analyses for the three species according to their respective maximal migration distances (MMD): (a) Bufo bufo, (b) Rana dalmatina, and (c) Lissotriton vulgaris. Species occurrence is represented by red (presence) and black (absence) circles

MMD. The pond-level relative influence decreased with the increase in MMD in the cases of R. dalmatina and L. vulgaris, while the opposite relationship was observed in the case of $B$. bufo (Table 3).

The WQI had a positive relationship with species occurrence, generally for a minimum value of $70 \%$, corresponding to the average level of good water quality (Figure 4). The distance to the nearest pond occupied by the focal species (DistOccPond) showed a strong negative relationship for L. vulgaris, also notable for R. dalmatina (Figure 4).
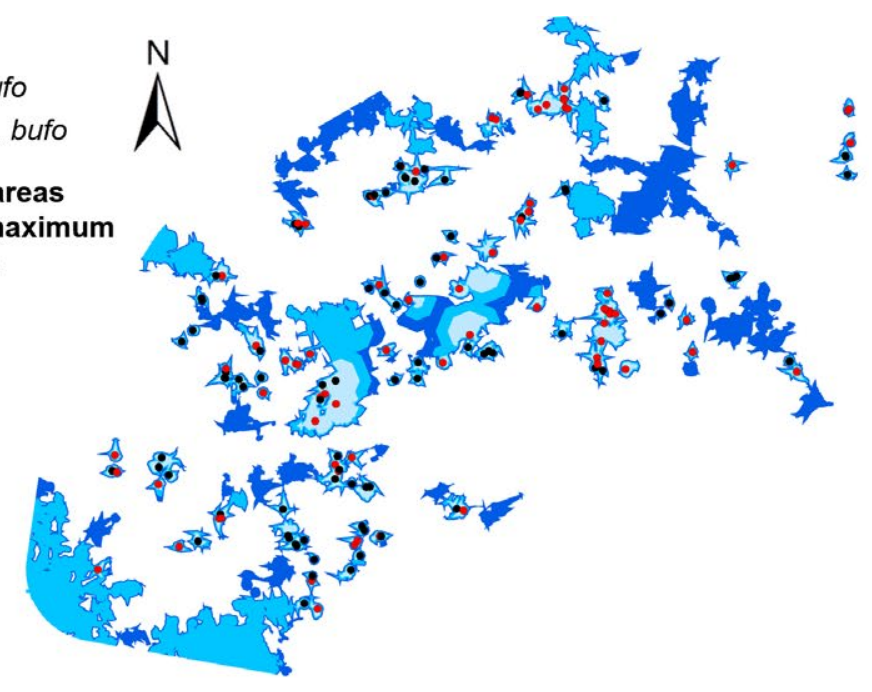

oni
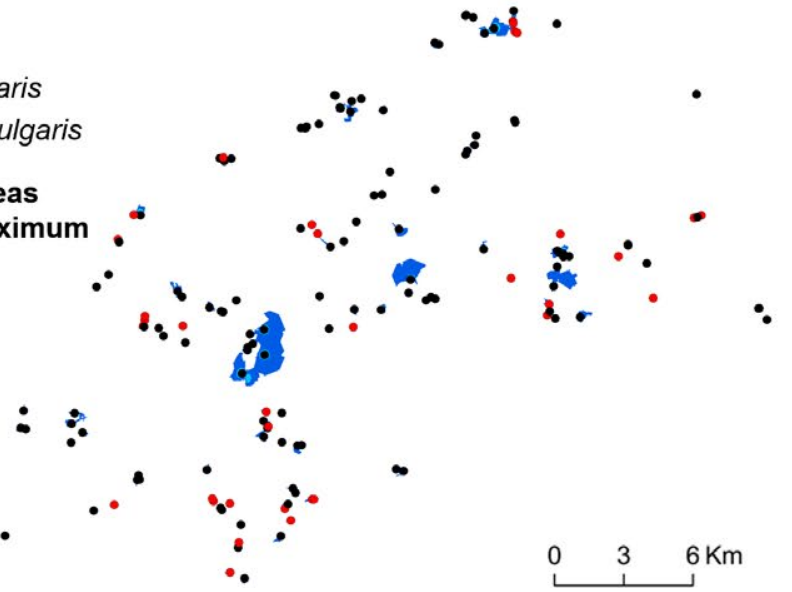

Boosted regression tree analysis highlights the interaction effects among pond-, pond-in-network-, and network-level variables, although most of the interaction effects had a relatively weak contribution to the deviance explained by the different predictors (Table 4a). The pond variables especially interacted with the higher-scale variables, i.e. with network and pondin-network variables in $40 \%$ and $25 \%$ of cases, respectively. Pond-scale variables also interacted with each other (20\%) (Table 4b). 


$\begin{array}{lll}2000 \mathrm{~m} & \square 1500 \mathrm{~m} & \square 1000 \mathrm{~m} \\ \text { DevPerc }=10 \% & \text { DevPerc }=16 \% & \text { DevPerc }=18 \%\end{array}$

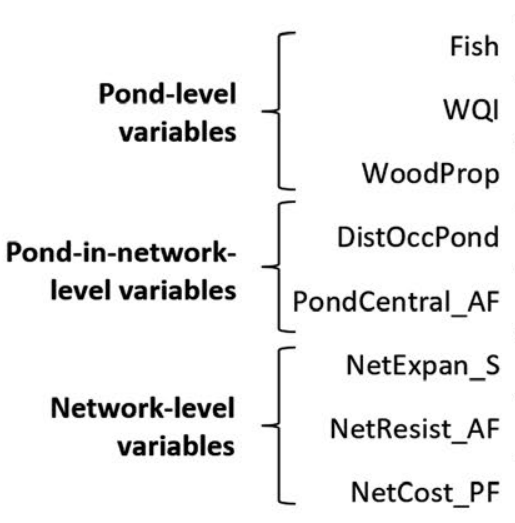

(b) Rana dalmatina

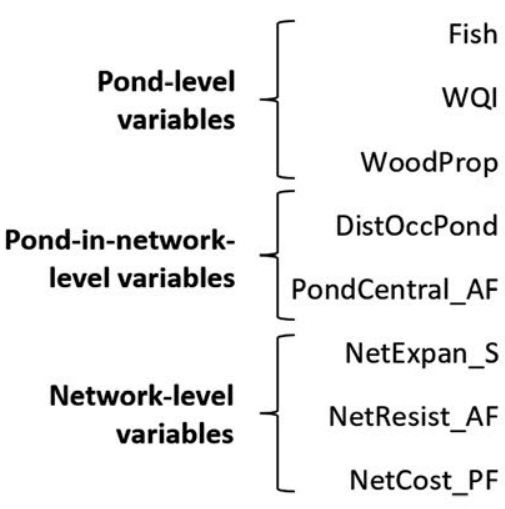

(c) Lissotriton vulgaris

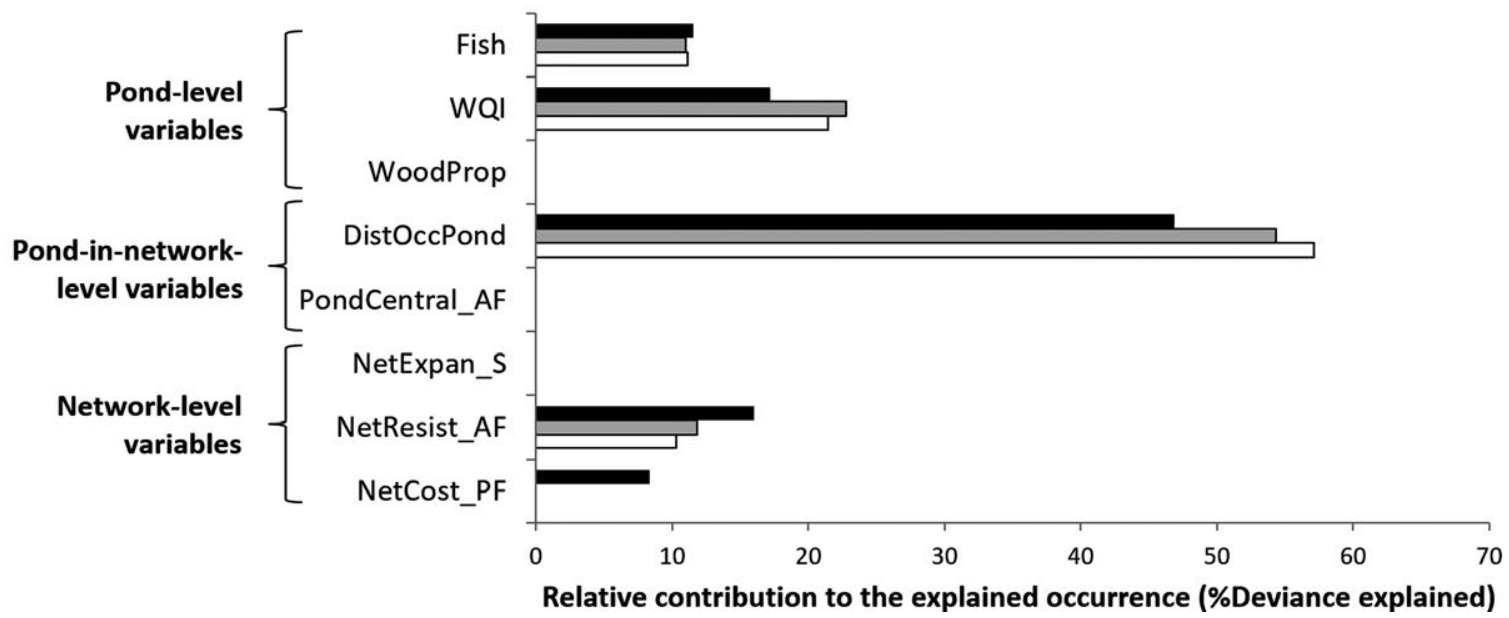

FIGURE 3 Ranking of local and network variables obtained from boosted regression tree analyses for the three species - (a) Bufo bufo, (b) Rana dalmatina, and (c) Lissotriton vulgaris - and for each migration distance considered after model simplification. The variables are coded according to Table 2. DevPerc = the percentage of deviance explained by the final model 
In particular, we observed a sharper decrease in the occurrence of $L$. vulgaris in response to fish when the water quality was better (Figure 5a). Pond variables can also interact with pond-in-networkscale variables such as DistOccPond (Figure 5b,c); e.g. the more connected the focal pond is, the stronger the response of $L$. vulgaris to water quality (Figure $5 b$ ). The same observation can be made for R. dalmatina in the case of fish presence (Figure $5 \mathrm{c}$ ). Interactions between pond- and network-scale variables showed how the positive response to connectivity can be moderately reduced by the negative effects of local conditions (Figure $5 \mathrm{~d}, \mathrm{e}$ ). Finally, we found only one small interaction between network variables for R. dalmatina, which involved network expansion and network resistance (Figure 5f).

\section{4 | DISCUSSION}

\subsection{Structural versus functional characteristics of connectivity in relation to amphibian distribution}

At the network influence scale, we showed the overall power of functional connectivity variables in explaining amphibian species distribution in line with previous studies (Joly et al., 2003; Ray et al., 2002). In particular, area-functional connectivity better explained the distribution of R. dalmatina and L. vulgaris compared to path-functional and structural connectivity. This was expected (hypothesis 1a) since this connectivity metric probably includes the effects of both aquatic and terrestrial habitat availability/quality (breeding sites, source of resources, shelters) and habitat connectivity (potential migration and dispersal routes). Another possible explanation is that the area-functional approach makes no particular assumption about the movement direction; it thus encompasses all possible paths an animal could take within the potential migration area. Although the movement directions for migration and dispersal were shown to be non-randomly distributed for several species (Marty, Angélibert, Giani, \& Joly, 2005; Sinsch, 2014), the directional movement might be highly disrupted in areas disturbed by human activities such as intensive agriculture (Mazerolle \& Desrochers, 2005).

However, in the case of B. bufo at shorter migration distance, structural connectivity explained almost as much of the species occurrence variation as functional connectivity. This suggests that in this range of migration distance, both network resistance and network expansion might be relevant predictors of toad distribution. Given the relatively better dispersal ability of B. bufo compared to the two other species (ACEMAV coll., 2003; Smith \& Green, 2005), we may be able to detect both the effects of network quality and network size. This result suggests that at the network scale, the functional and structural features of the connectivity should not be treated exclusively, but rather in complementarity to get a more complete view of the ecological connectivity in a system.

At the pond-in-network influence scale, the distance to the nearest occupied pond remained a good predictor of species occurrence, in particular for L. vulgaris, and outperformed the functional pond centrality, contrary to our prediction in (1b). Moilanen and Nieminen (2002) reviewed that the distance to potential source populations was an effective predictor of habitat use, colonisation, extinction, and population genetic differentiation in the particular case of amphibians in highly fragmented habitats. The sensitivity of amphibians regarding the distance to the nearest occupied pond is often attributed to metapopulation processes and individuals' movements between close ponds, but it can also be due to habitat availability for adults (Van Buskirk, 2005). In our case, the metapopulation hypothesis cannot be rejected because the distance to the nearest occupied pond (considering ponds as potential sources of propagules) showed greater effect than the degree centrality (considering ponds as potential available habitats in the surrounding, i.e. ponds that are not necessarily occupied by the species). However, to test this hypothesis in our framework, we would need to improve the parameterisation of our networks so that they better reflect the actual ecological requirements of this species.

\section{2 | Cross-scale effects of pond and network variables on species distribution}

\subsubsection{Main effects of pond and network variables across spatial scales}

The pond-scale effects on both anurans' occurrence usually dominated the other scales. Habitat preference, including for reproduction, may thus be one major limiting process underlying their population persistence in this landscape (e.g. Van Buskirk, 2005). By contrast, $L$. vulgaris was especially responsive to pond isolation with a sharp negative relationship, suggesting that its distribution has a strong spatial auto-correlation and may rely on source-sink processes (Harrison, 1991) or on rescue effects.

At the network scale, reduced connectivity had the expected negative effects on pond occupancy probability for both anurans (1c), but a positive effect on L. vulgaris in terms of both network resistance and accumulated cost for joining the focal pond. In a study about the links between landscape permeability and amphibian migration, Lenhardt et al. (2013) showed that woodland areas had a good habitat suitability for $L$. vulgaris and thus used low cost values for woodland areas. We used this study to set the resistance values of woodlots for this species. However, in other studies, L. vulgaris occurrence has proven to be rather favoured by open landscapes, especially grasslands, and even positively responded to the distance to the nearest woodland (Denoël \& Ficetola, 2007). This could explain the positive link we find for network resistance, although there are still contradicting results about the effect of the distance to the nearest forest on this species (Table 2 in Denoël et al., 2013). If woodlands constitute actual barriers for L. vulgaris, our evaluation according to which the tree-filled areas were favourable habitats might be reconsidered (Garshelis, 2000). The results for L. vulgaris are also difficult to interpret as they include many isolated ponds for which the measure 
(a) B. bufo $(1,000 \mathrm{~m})$
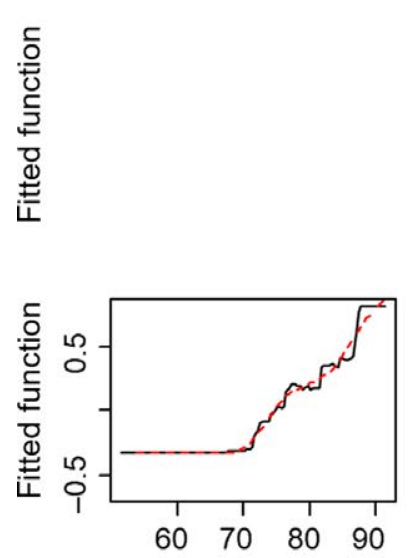

든

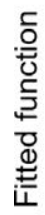

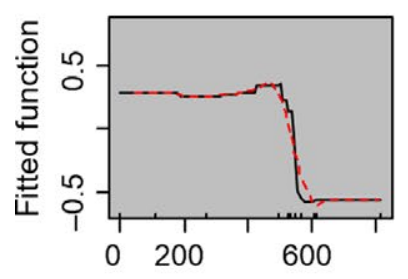

NetExpan_S (30.4\%)

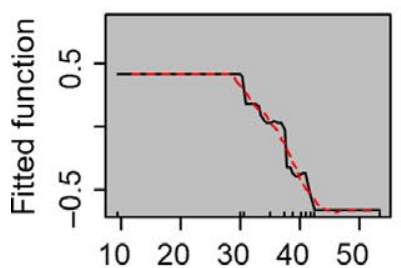

NetResist_AF (32.1\%)

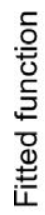

(b) R. dalmatina $(1,000 \mathrm{~m})$

(c) L. vulgaris $(800 \mathrm{~m})$
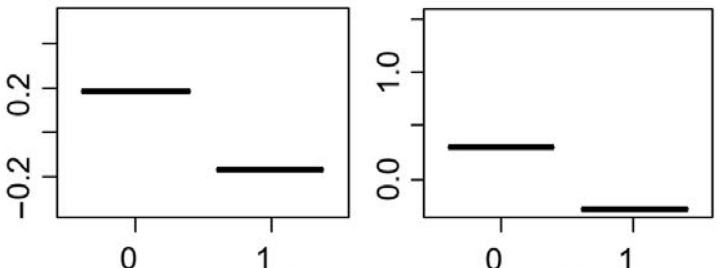

Fish (14.2\%)

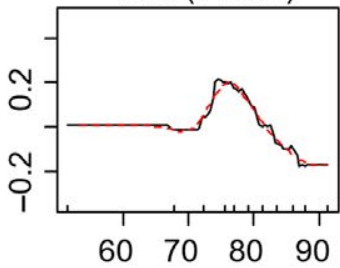

WQI $(12.8 \%)$
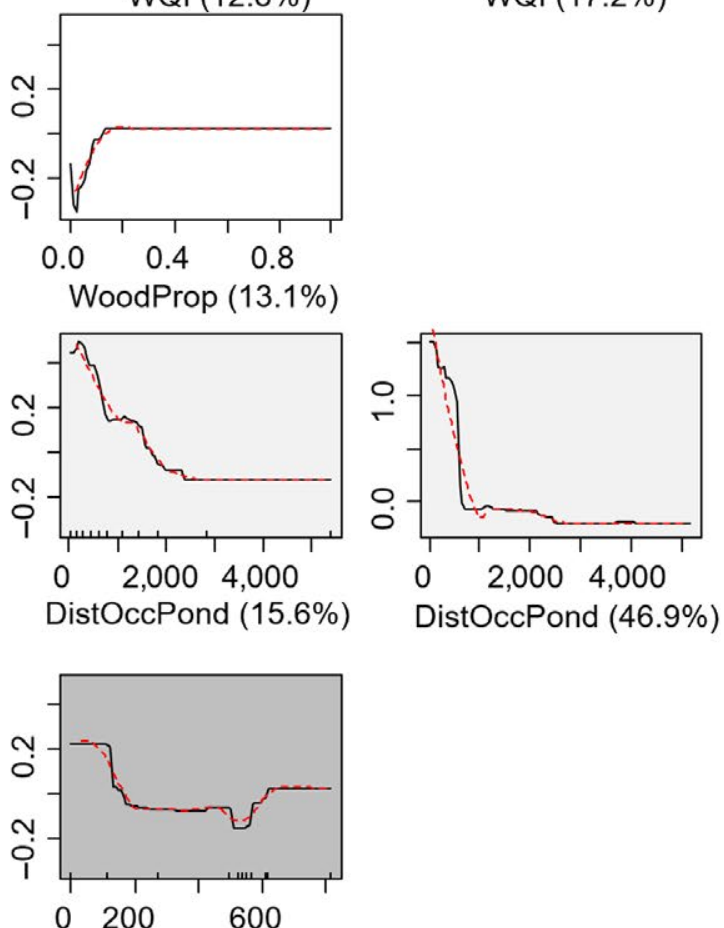

NetExpan_S (12.9\%)

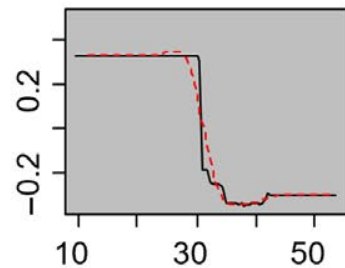

NetResist_AF (18.7\%)

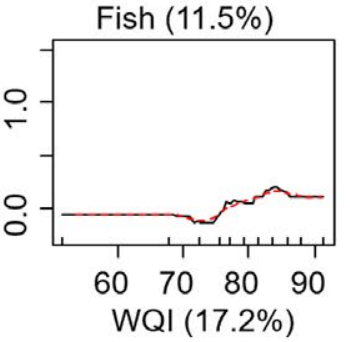

DistOccPond (46.9\%)
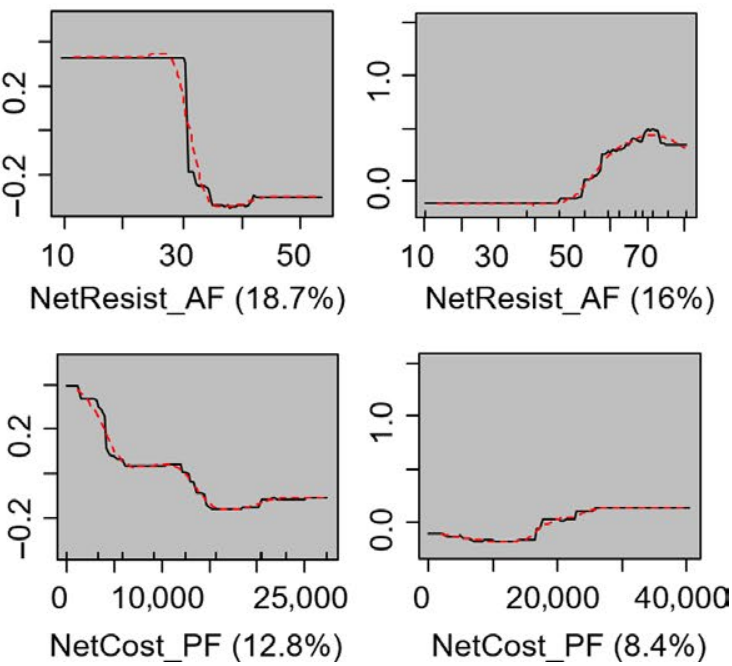

FIGURE 4 Plots of the boosted regression tree-fitted relationships of species occurrence in response to pond(white), pond-in-network- (light grey), and network-scale (dark grey) variables (Table 2) for (a) Bufo bufo in the $1,000 \mathrm{~m}$ model, (b) Rana dalmatina in the $1,000 \mathrm{~m}$ model, and (c) Lissotriton vulgaris in the $800 \mathrm{~m}$ model. Only the variables selected by the final models are shown. The relative percentages of explained deviance are shown in parenthesis 
TAB LE 3 Ranking of the three scales of influence (pond, P; pond-in-network, PN; network, N) on species occurrence according to the total amount of deviance explained by the variables from each tested scale, species, and maximal migration distance (MMD); in grey, the best models in terms of deviance explained

\begin{tabular}{|c|c|c|c|}
\hline Species & MMDmin & MMDmed & MMDmax \\
\hline Bufo bufo & $\mathrm{N} \gg \mathrm{P} \gg \mathrm{PN}$ & $\mathrm{P}>\mathrm{N}>\mathrm{PN}$ & $\mathrm{P} \gg \mathrm{N}>\mathrm{PN}$ \\
\hline Rana dalmatina & $\mathrm{P} \gg \mathrm{PN} \gg \mathrm{N}$ & $\mathrm{P} \gg \mathrm{N}>\mathrm{PN}$ & $\mathrm{N}>\mathrm{P}>\mathrm{PN}$ \\
\hline $\begin{array}{c}\text { Lissotriton } \\
\text { vulgaris }\end{array}$ & $\mathrm{PN}>\mathrm{P}>\mathrm{N}$ & $\mathrm{PN}>\mathrm{P}>\mathrm{N}$ & $\mathrm{PN}>\mathrm{P}>\mathrm{N}$ \\
\hline
\end{tabular}

of network resistance actually corresponds to a measure of habitat quality rather than connectivity.

The relative ranking of influences from pond, pond-in-network, and network scales varies depending on the species, which gives some insights about the specific differences in the dominating scales of influence. For instance, B. bufo is more responsive to network-scale influences whereas $L$. vulgaris is rather responsive to pond-in-networkscale influence. This could be explained by strong differences in their dispersal limitations or in their spatial orientation (e.g. Sinsch \& Kirst, 2016). We need further investigations to conclude about what are the actual processes that underlie these species' distribution.

TAB LE 4 Full list (a) and summary (b) of the most important interactions detected using the boosted regression tree procedure modelling species occurrence in response to pond- (P), pond-in-network- (PN), and network-level (N) variables for Bufo bufo (Buf) under MMD of 1,000, 1,500, and 2,000 m; Rana dalmatina (Ran) under MMD of 300, 500, and 1,000 m; and Lissotriton vulgaris (Tri) under MMD of 100, 200, and $800 \mathrm{~m}$. The interaction size refers to the relative contribution of the interaction to the explained deviance compared to a model where no interaction is considered. In a), Highlighted in grey are the interactions plotted in Figure 5

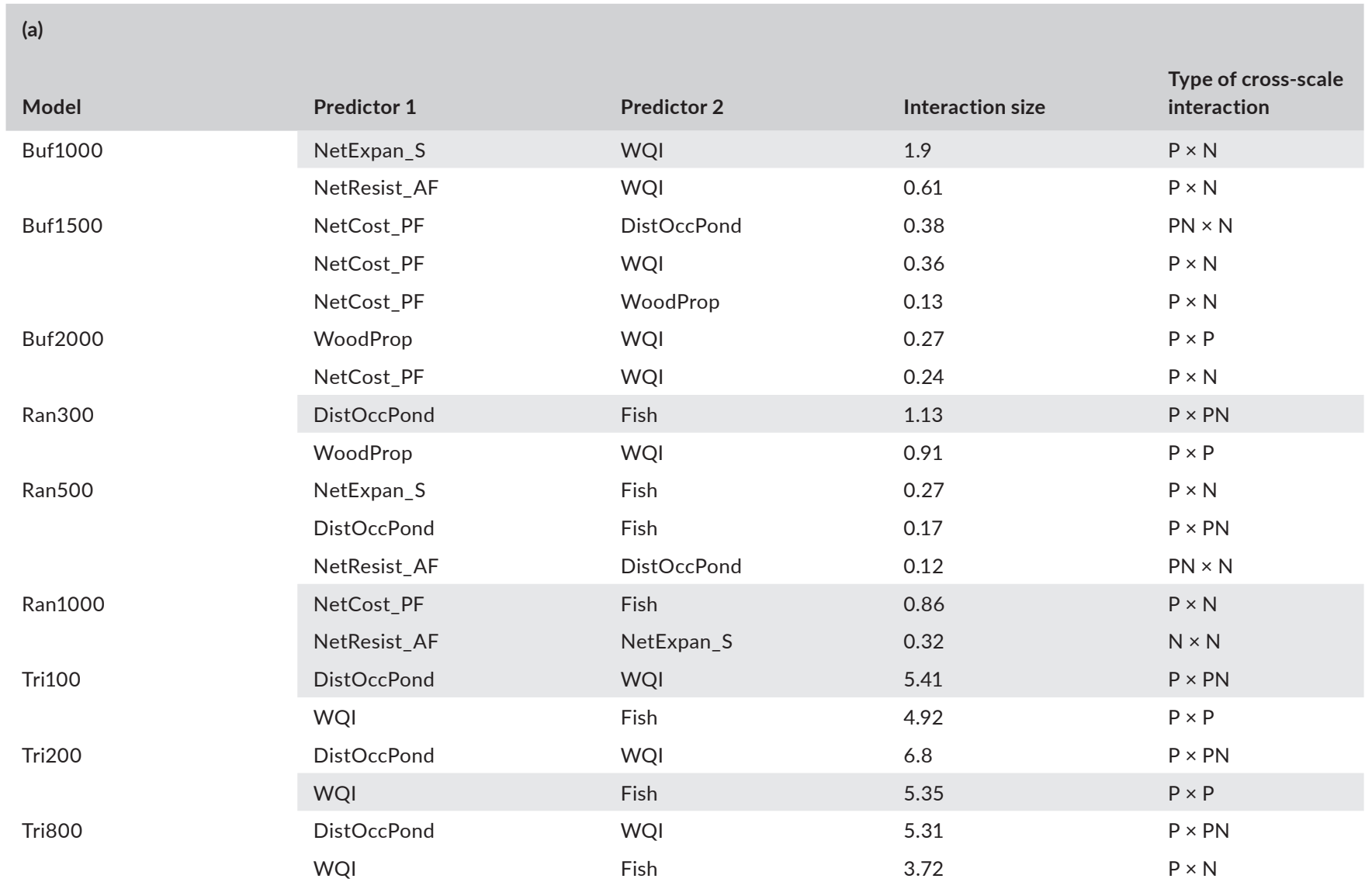

\begin{tabular}{lcc} 
(b) & & \\
Type of cross-scale interaction & Number of interactions detected across all models & Proportion of interactions detected across all models \\
\hline $\mathrm{P} \times \mathrm{N}$ & 8 & 40 \\
$\mathrm{P} \times \mathrm{PN}$ & 5 & 25 \\
\hline $\mathrm{P} \times \mathrm{P}$ & 4 & 20 \\
$\mathrm{PN} \times \mathrm{N}$ & 2 & 10 \\
$\mathrm{~N} \times \mathrm{N}$ & 1 & 5 \\
\hline Total & 20 & 100 \\
\hline
\end{tabular}




\section{Pond*Pond}

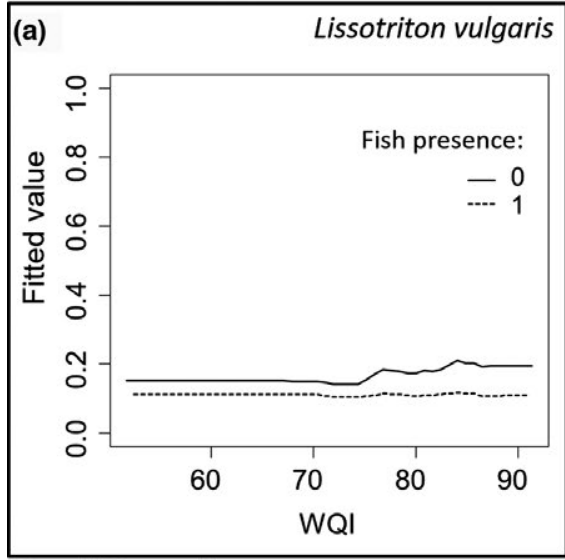

Pond*Network

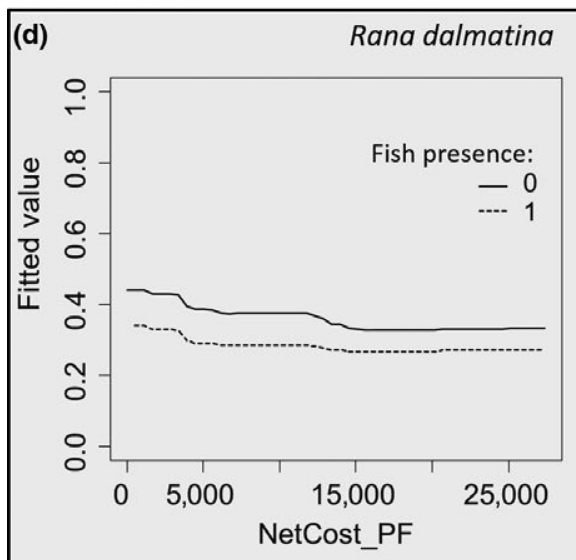

Pond*Pond-in-network

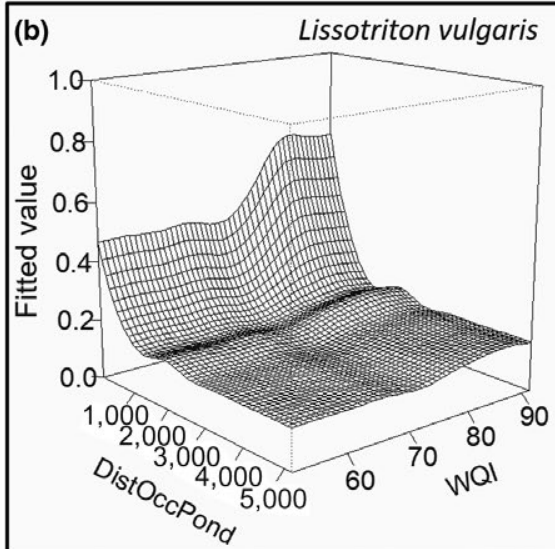

(c)

Rana dalmatina

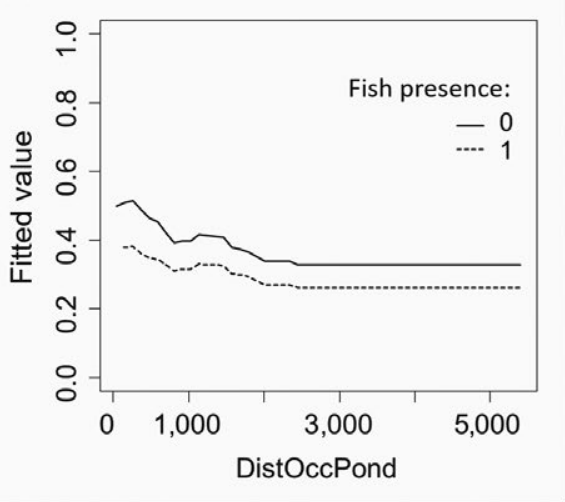

Network*Network
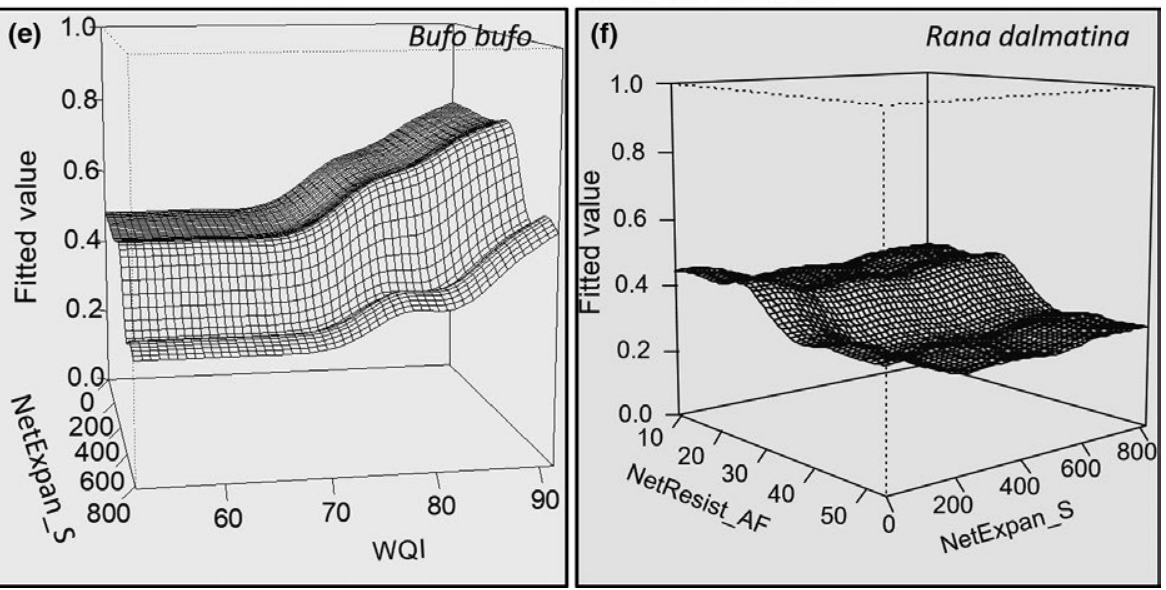

FIGURE 5 Plots illustrating the major interaction effects selected and estimated by boosted regression tree models of species occurrence involving (a) only pond, (b, c) pond and pond-in-network, (d, e), pond and network, and (f) network variables for Lissotriton vulgaris under maximal migration distances (MMD) of $100 \mathrm{~m}$ (b), $200 \mathrm{~m}$ (a), Rana dalmatina under MMD of $300 \mathrm{~m}$ (c) and 1,000 m (d, f), and Bufo bufo under MMD of $1,000 \mathrm{~m}(\mathrm{e})$

\subsubsection{Interaction effects of pond and network variables across spatial scales}

The interaction effects were relatively small compared to the main effects. Nevertheless, our results support the existence of crossscale effects in amphibian-environment relationships (Werner et al., 2014), especially between pond and network scales. As expected in (2a), the positive relationship with network connectivity was usually amplified in the presence of good water quality and the absence of fish. (Reciprocally, a poor water quality and the presence of fish would annihilate the positive relationship with connectivity by impeding the settlement of population-ponds would then become sinks.) Although the detection of interactions at the network scale was more arduous-probably due to an increase of complexity-we showed that the network expansion could amplify the negative effect of network resistance as predicted in (2b). Overall, these results highlight that the different processes shaping species distribution are likely to operate and interact with each other across a gradient of scales.

\section{3 | Methodological insights and challenges for a cross-scale expertise of ecological connectivity}

The overall performance of our models showed substantial sensitivity to the species maximum migration distances modelled. This sensitivity gives some indications about the relevance of the range of maximum distances used for each species. It generally suggested that for the anuran species, the distance of c. 1,000 m was relevant to capture the potential effects of both dispersal limitation (connectivity metrics), habitat suitability (local conditions), and possibly habitat complementarity (Janin et al., 2009). We may have tested ranges at the limit and overestimated the potential migration distances for B. bufo (e.g. Sztatecsny \& Schabetsberger, 2005). However, the ranges we tested remain overall in the same order of magnitude than the ones found in most of the radio-tracking studies (Smith \& Green, 2005). The fact that the models based on $300 \mathrm{~m}$ and $1,000 \mathrm{~m}$ performed equally well for R. dalmatina, also in accordance with Lemckert (2004), and might indicate different movement patterns. For instance, natal dispersal has been shown to operate at 
greater distances than adult habitat use in some anuran species (e.g. Angelone, Kienast, \& Holderegger, 2011).

Note that even though the migration distances were chosen within a reasonable range based on previous works (Supporting Information Appendix S2), the ranking of predictors also changed depending on these distances. This suggests that using only one distance would have led to biased or incomplete conclusions about the dominating scales of influence. Given our still scattered knowledge about movement patterns and distances for amphibian species, it seems reasonable to test as many distances as possible.

We used biological risk-based criteria related to vegetation stratum to classify landscape features and assign them resistance coefficients. This approach, despite deriving from expert knowledge, is more transparent, standardised, and evaluable than a classical, fuzzy expert-based approach, as it relies on a framework of explicit hypotheses along with the relevant literature. Other approaches directly estimated ecological connectivity based on biological data from either species distribution (Janin et al., 2009), population genetic structure (Stevens, Verkenne, Vandewoestijne, Wesselingh, \& Baguette, 2006), or radio-tracking (Smith \& Green, 2005). When such data are available in good quality and with reasonable spatial coverage, it seems highly recommendable to use them for connectivity analyses, as they avoid the need to subjectively choose resistance values. Otherwise, the risk-based approach is a good alternative for guiding cost-effective, applied conservation (Supporting Information Appendix S8).

\subsection{Thresholds in local and connectivity effects: Implications for amphibian conservation in agricultural landscapes}

The detection of cross-scale effects of the environment on species occurrence proves that our analysis design gives a reasonable picture of the intrinsic scales ( $\mathrm{Wu} \& \mathrm{Li}, 2006$ ) at which processes may operate in shaping species distribution. Our approach integrates multi-level processes (Peters et al., 2007). It should be considered for more effective pond management (Semlitsch, 2002) to design management units that have ecologically meaningful contours and spatial cohesion at the landscape scale.

As predicted in (3), we showed the existence of thresholds in the species occurrence probability in response to predictors from different scales. The existence of such threshold values for habitat connectivity is consistent with the principle of percolation theory (Stauffer \& Aharony, 1992). Critical connectivity thresholds emerge when the abundance and arrangement of favourable patches, as well as the displacement abilities of the species, become limiting.

The responses to local conditions such as water quality differed quantitatively among the three species, thus reflecting the differential habitat selection of these species. Connectivity results also highlighted potential optimal pond networks for these species in agricultural contexts. For B. bufo, the appropriate network would have a mean resistance below 40 corresponding to half-woodland and half-crop areas, comprising at least seven ponds (one focal pond connected to six ponds) with a WQI above $70 \%$ and separated by $<500 \mathrm{~m}$, or by least-cost paths measuring $<1,500 \mathrm{~m}$ and crossing low resistance features (e.g. woodlands, continuous shrub hedges). Similarly, a potentially viable pond network for $R$. dalmatina could, as a minimum, have a mean network resistance below 30 , include fishless ponds separated by $<200 \mathrm{~m}$, and be immediately surrounded by more than $20 \%$ of woody areas. Finally, in the case of L. vulgaris, one should favour patchy networks in more open areas with inter-pond distances not exceeding $800 \mathrm{~m}$. These simple statements allow us to highlight the threshold values that could be used as general guidance to orientate pondscape (Boothby, 1997) management in agricultural areas according to a network strategy.

\section{5 | CONCLUSION}

Our work provides an original analytical framework for investigating the multifactorial relationships between amphibian distribution and environment, and highlighting cross-scale effects and nonlinearities in amphibian response to habitat quality and connectivity. We integrated in one single study all the aspects that have usually been addressed separately when studying amphibian distribution. We thus addressed the different scales of influence from pond to network scales, their relative importance and the way they interact, the buffer-based versus network-based and the structural versus functional approaches of connectivity. We emphasised the relevance of network approaches as a complement to pond-centred approaches for amphibian conservation (Boothby, 1997; Roe \& Georges, 2007). We encourage conservation plans to adopt functional network-centred strategies based on potential migration areas as relevant ecological units (Ray et al., 2002). We give clear guidelines as to the features of such networks to help maintain amphibian populations in agricultural landscapes. Our results and approach can help stakeholders to find possible compromises between the constraints inherent to agricultural activities and the conservation of biodiversity in these areas.

\section{ACKNOWLEDGMENTS}

The Fédération d'lle-de-France pour la Recherche en Environnement (FIRE FR-3020) is greatly acknowledged for the PhD grant awarded to Alienor Jeliazkov. We also thank Annabelle Boucher (NATUREPARIF), Vincent Vignon (OGE), Pierre Joly (UMR 5023), Dirk Schmeller (UFZ), SNPN, and Département de Seineet-Marne for their help, advice, and support. Thanks are due to Pierre Rivallin (Seine-et-Marne Environnement) for providing early training with species identification and to Benjamin Mercier (UPMC) for the water analyses. We are also grateful to the student interns, Fabien Michel, Flora Guillier, Victor Court, Pietro Viacava, Nicolas El Battari, Elodie Rey, and others for their help on the field. We are grateful to the landowners, farmers, and authorities from Seine-et-Marne. 


\section{CONFLICT OF INTEREST}

The authors declare no conflict of interest.

\section{ORCID}

Alienor Jeliazkov (iD https://orcid.org/0000-0001-5765-3721

Romain Lorrillière (iD https://orcid.org/0000-0003-1870-0278

Aurélien Besnard iD https://orcid.org/0000-0002-2289-9761

Josette Garnier (iD https://orcid.org/0000-0001-9416-9242

Marie Silvestre iD https://orcid.org/0000-0002-9508-7705

François Chiron (iD https://orcid.org/0000-0001-9352-2390

\section{REFERENCES}

ACEMAV coll. (2003). Les Amphibiens de France, Belgique et Luxembourg. R. Duguet \& F. Melki (Eds.), Mèze, France: Biotope.

Allen, T. F., \& Starr, T. B. (1982). Hierarchy: Perspectives for ecological complexity. Chicago, IL: University of Chicago Press.

Angelone, S., Kienast, F., \& Holderegger, R. (2011). Where movement happens: Scale-dependent landscape effects on genetic differentiation in the European tree frog. Ecography, 34, 714-722. https://doi. org/10.1111/j.1600-0587.2010.06494.x

Arnold, N., \& Ovenden, D. (2014). Le guide herpéto - Amphibiens et reptiles d'Europe. Paris, France: Delachaux.

Baguette, M., \& Van Dyck, H. (2007). Landscape connectivity and animal behavior: Functional grain as a key determinant for dispersal. Landscape Ecology, 22, 1117-1129. https://doi.org/10.1007/ s10980-007-9108-4

Bartelt, P. E., Klaver, R. W., \& Porter, W. P. (2010). Modeling amphibian energetics, habitat suitability, and movements of western toads, Anaxyrus (=Bufo) boreas, across present and future landscapes. Ecological Modelling, 221, 2675-2686. https://doi.org/10.1016/j. ecolmodel.2010.07.009

Bennett, A. F. (2003). Linkages in the landscape: The role of corridors and connectivity in wildlife conservation. Gland, Switzerland and Cambridge, UK: IUCN. https://doi.org/10.2305/iucn.ch.2004.fr.1.en

Boothby, J. (1997). Pond conservation: Towards a delineation of pondscape. Aquatic Conservation: Marine and Freshwater Ecosystems, 7, 127-132. https://doi.org/10.1002/(issn)1099-0755

Calabrese, J. M., \& Fagan, W. F. (2004). A comparison-shopper's guide to connectivity metrics. Frontiers in Ecology and the Environment, 2, 529-536. https://doi.org/10.1890/1540-9295(2004)002[052 9:acgtcm]2.0.co;2

Chase, J. M., \& Ryberg, W. A. (2004). Connectivity, scale-dependence, and the productivity-diversity relationship. Ecology Letters, 7, 676683. https://doi.org/10.1111/j.1461-0248.2004.00622.x

Clauzel, C., Girardet, X., \& Foltête, J.-C. (2013). Impact assessment of a high-speed railway line on species distribution: Application to the European tree frog (Hyla arborea) in Franche-Comté. Journal of Environmental Management, 127, 125-134. https://doi.org/10.1016/j. jenvman.2013.04.018

Cushman, S. A. (2006). Effects of habitat loss and fragmentation on amphibians: A review and prospectus. Biological Conservation, 128, 231-240. https://doi.org/10.1016/j.biocon.2005.09.031

Cushman, S., Compton, B., \& McGarigal, K. (2010). Habitat fragmentation effects depend on complex interactions between population size and dispersal ability: Modeling influences of roads, agriculture and residential development across a range of life-history characteristics. In S. Cushman, \& F. Huettmann (Eds.), Spatial complexity, informatics, and wildlife conservation (pp. 369-385). Tokyo, Berlin, Heidelberg and New York: Springer Science \& Business Media.

De'ath, G. (2007). Boosted trees for ecological modeling and prediction. Ecology, 88, 243-251. https://doi.org/10.1890/0012-9658(2007)88 [243:btfema]2.0.co;2

Decout, S., Manel, S., Miaud, C., \& Luque, S. (2012). Integrative approach for landscape-based graph connectivity analysis: A case study with the common frog (Rana temporaria) in human-dominated landscapes. Landscape Ecology, 27, 267-279. https://doi.org/10.1007/ s10980-011-9694-z

Denoël, M., \& Ficetola, G. F. (2007). Landscape-level thresholds and newt conservation. Ecological Applications, 17, 302-309. https://doi. org/10.1890/1051-0761(2007)017[0302:Itanc]2.0.co;2

Denoël, M., \& Ficetola, G. F. (2008). Conservation of newt guilds in an agricultural landscape of Belgium: The importance of aquatic and terrestrial habitats. Aquatic Conservation: Marine and Freshwater Ecosystems, 18, 714-728. https://doi.org/10.1002/aqc.853

Denoël, M., Perez, A., Cornet, Y., \& Ficetola, G. F. (2013). Similar local and landscape processes affect both a common and a rare newt species. PLoS ONE, 8, e62727. https://doi.org/10.1371/journal.pone.0062727

Département de Seine-et-Marne \& SNPN (2012). Inventaire des mares d'lle-de-France. Etat des lieux 2011 et perspectives 2012. Département de Seine-et-Marne \& Société Nationale de la Protection de la Nature.

Elith, J., Leathwick, J. R., \& Hastie, T. (2008). A working guide to boosted regression trees. Journal of Animal Ecology, 77, 802-813. https://doi. org/10.1111/j.1365-2656.2008.01390.x

Etherington, T. R., \& Holland, P. E. (2013). Least-cost path length versus accumulated-cost as connectivity measures. Landscape Ecology, 28, 1223-1229. https://doi.org/10.1007/s10980-013-9880-2

Ficetola, G. F., Marziali, L., Rossaro, B., Bernardi, F. D., \& Padoa-Schioppa, E. (2011). Landscape-stream interactions and habitat conservation for amphibians. Ecological Applications, 21, 1272-1282. https://doi. org/10.1890/10-0431.1

Fischer, J., \& Lindenmayer, D. B. (2007). Landscape modification and habitat fragmentation: A synthesis. Global Ecology and Biogeography, 16, 265-280. https://doi.org/10.1111/j.1466 -8238.2007.00287.x

Fortuna, M. A., Gomez-Rodriguez, C., \& Bascompte, J. (2006). Spatial network structure and amphibian persistence in stochastic environments. Proceedings of the Royal Society B: Biological Sciences, 273, 1429-1434. https://doi.org/10.1098/rspb.2005.3448

Galpern, P., \& Manseau, M. (2013). Finding the functional grain: Comparing methods for scaling resistance surfaces. Landscape Ecology, 28, 1269-1281. https://doi.org/10.1007/s10980-013-9873-1

Garshelis, D. L. (2000). Delusions in habitat evaluation: Measuring use, selection, and importance: Measuring use, selection, and importance. Research techniques in animal ecology: Controversies and consequences (pp. 111-164). New York, NY: Columbia University Press.

Guerry, A., \& Hunter, M. (2002). Amphibian distributions in a landscape of forests and agriculture: An examination of landscape composition and configuration. Conservation Biology, 16, 745-754. https://doi. org/10.1046/j.1523-1739.2002.00557.x

Guisan, A., \& Thuiller, W. (2005). Predicting species distribution: Offering more than simple habitat models. Ecology Letters, 8, 993-1009. https://doi.org/10.1111/j.1461-0248.2005.00792.x

Gunzburger, M., \& Travis, J. (2005). Critical literature review of the evidence for unpalatability of amphibian eggs and larvae. Journal of Herpetology, 39, 547-571. https://doi.org/10.1670/1-05a.1

Harrison, S. (1991). Local extinction in a metapopulation context: An empirical evaluation. Biological Journal of the Linnean Society, 42, 73-88. https://doi.org/10.1111/j.1095-8312.1991.tb00552.x

Hijmans, R.J., Phillips, S., Leathwick, J., \& Elith, J. (2016). dismo: Species distribution modeling. Retrieved from https://CRAN.R-project.org/ package $=$ dismo 
Hilty, J. A., Lidicker, W. Z., Merenlender, A., \& Dobson, A. P. (2006). Corridor ecology: The science and practice of linking landscapes for biodiversity conservation. Washington, Covelo and London: Island Press.

IAU IDF (2005). Ecomos 2000 - Atlas des Milieux Naturels En Ile-deFrance. Retrieved from http://www.natureparif.fr/observer/ cartographie-indicateurs/ecomos

IAU IDF (2008). MOS - Mode d'Occupation du Sol de la région lle-de-France. Retrieved from http://www.iau-idf.fr/detail/etude/mode-doccupation-du-sol-de-la-region-ile-de-france.html

IAU IDF (2012). Ecoline - Elements singuliers des espaces ruraux d'lle-deFrance. Retrieved from http://www.iau-idf.fr/detail/etude/ecoline-lacartographie-des-elements-de-biodiversite-des-paysages-ruraux. html

IGN (2008). BD TOPO ${ }^{\circledR} v 2$. Descriptif de contenu. Retrieved from http:// professionnels.ign.fr/sites/default/files/DC_BDORTHO_2.pdf

Janin, A., Léna, J.-P., Deblois, S., \& Joly, P. (2012). Use of stress-hormone levels and habitat selection to assess functional connectivity of a landscape for an amphibian. Conservation Biology, 26, 923-931. https://doi.org/10.1111/j.1523-1739.2012.01910.x

Janin, A., Léna, J.-P., \& Joly, P. (2011). Beyond occurrence: Body condition and stress hormone as integrative indicators of habitat availability and fragmentation in the common toad. Biological Conservation, 144, 1008-1016. https://doi.org/10.1016/j.biocon.2010.12.009

Janin, A., Léna, J. P., Ray, N., Delacourt, C., Allemand, P., \& Joly, P. (2009). Assessing landscape connectivity with calibrated cost-distance modelling: Predicting common toad distribution in a context of spreading agriculture. Journal of Applied Ecology, 46, 833-841. https://doi. org/10.1111/j.1365-2664.2009.01665.x

Jeliazkov, A. (2013). Scale-effects in agriculture-environment-biodiversity relationships. Paris, France: Université Pierre et Marie Curie.

Jeliazkov, A., Chiron, F., Garnier, J., Besnard, A., Silvestre, M., \& Jiguet, F. (2014). Level-dependence of the relationships between amphibian biodiversity and environment in pond systems within an intensive agricultural landscape. Hydrobiologia, 723, 7-23. https://doi. org/10.1007/s10750-013-1503-z

Joly, P., Morand, C., \& Cohas, A. (2003). Habitat fragmentation and amphibian conservation: Building a tool for assessing landscape matrix connectivity. Comptes Rendus Biologies, 326, 132-139. https://doi. org/10.1016/s1631-0691(03)00050-7

Kats, L. B., Petranka, J. W., \& Sih, A. (1988). Antipredator defenses and the persistence of amphibian larvae with fishes. Ecology, 69, 18651870. https://doi.org/10.2307/1941163

Lawler, J. J., \& Edwards, T. C. Jr (2006). A variance-decomposition approach to investigating multiscale habitat associations. The Condor, 108, 47-58. https://doi.org/10.1650/0010-5422(2006)108[0047: avatim]2.0.co;2

Lemckert, F. L. (2004). Variations in anuran movements and habitat use: Implications for conservation. Applied Herpetology, 1, 165-181. https://doi.org/10.1163/157075403323012179

Lenhardt, P. P., Schäfer, R. B., Theissinger, K., \& Brühl, C. A. (2013). An expert-based landscape permeability model for assessing the impact of agricultural management on amphibian migration. Basic and Applied Ecology, 14, 442-451. https://doi.org/10.1016/j. baae.2013.05.004

Levin, S. A. (1992). The problem of pattern and scale in ecology. Ecology, 73, 1943-1967. https://doi.org/10.2307/1941447

Marty, P., Angélibert, S., Giani, N., \& Joly, P. (2005). Directionality of preand post-breeding migrations of a marbled newt population (Triturus marmoratus): Implications for buffer zone management. Aquatic Conservation: Marine and Freshwater Ecosystems, 15, 215-225. https://doi.org/10.1002/(issn)1099-0755

Mazerolle, M. J., \& Desrochers, A. (2005). Landscape resistance to frog movements. Canadian Journal of Zoology, 83, 455-464. https://doi. org/10.1139/z05-032
Metzger, J., \& Décamps, H. (1997). The structural connectivity threshold: An hypothesis in conservation biology at the landscape scale. Acta Oecologica, 18, 1-12. https://doi.org/10.1016/ s1146-609x(97)80075-6

Moilanen, A., \& Nieminen, M. (2002). Simple connectivity measures in spatial ecology. Ecology, 83, 1131-1145. https://doi.org/10.1890/00 12-9658(2002)083[1131:scmise]2.0.co;2

Neill, W. T. (1948). Hibernation of amphibians and reptiles in Richmond County, Georgia. Herpetologica, 4, 107-114.

Noss, R. F. (1991). Landscape connectivity: Different functions at different scales. In: W.E. Hudson (Ed.), Landscape linkages and biodiversity, Island Pre (pp. 27-39). Washington, DC: Hudson.

O'Neill, R. V., Johnson, A. R., \& King, A. W. (1989). A hierarchical framework for the analysis of scale. Landscape Ecology, 3, 193-205. https:// doi.org/10.1007/bf00131538

Patrick, D. A., Gibbs, J. P., Popescu, V. D., \& Nelson, D. A. (2012). Multi-scale habitat-resistance models for predicting road mortality "hotspots" for turtles and amphibians. Herpetological Conservation and Biology, 7, 407-426.

Pellet, J., Hoehn, S., \& Perrin, N. (2004). Multiscale determinants of tree frog (Hyla arborea L.) calling ponds in western Switzerland. Biodiversity and Conservation, 13, 2227-2235. https://doi. org/10.1023/b:bioc.0000047904.75245.1f

Pesce, S. F., \& Wunderlin, D. A. (2000). Use of water quality indices to verify the impact of Cordoba City (Argentina) on Suquia River. Water Research, 34, 2915-2926. https://doi.org/10.1016/ s0043-1354(00)00036-1

Peters, D. P. C., Bestelmeyer, B. T., \& Turner, M. G. (2007). Crossscale interactions and changing pattern-process relationships: Consequences for system dynamics. Ecosystems, 10, 790-796. https://doi.org/10.1007/s10021-007-9055-6

Prugh, L. R. (2009). An evaluation of patch connectivity measures. Ecological Applications, 19, 1300-1310. https://doi. org/10.1890/08-1524.1

R Core Team (2016). R: A language and environment for statistical computing. Vienna, Austria: R Foundation for Statistical Computing. Retrieved from http://www.R-project.org/

Ray, N., Lehmann, A., \& Joly, P. (2002). Modeling spatial distribution of amphibian populations: A GIS approach based on habitat matrix permeability. Biodiversity and Conservation, 11, 2143-2165. https://doi. org/10.1023/a:1021390527698

Reading, C. J., Loman, J., \& Madsen, T. (2009). Breeding pond fidelity in the common toad, Bufo bufo. Journal of Zoology, 225, 201-211.

Ribeiro, R., Carretero, M. A., Sillero, N., Alarcos, G., Ortiz-Santaliestra, M., Lizana, M., \& Llorente, G. A. (2011). The pond network: Can structural connectivity reflect on (amphibian) biodiversity patterns? Landscape Ecology, 26, 673-682. https://doi.org/10.1007/ s10980-011-9592-4

Roe, J., \& Georges, A. (2007). Heterogeneous wetland complexes, buffer zones, and travel corridors: Landscape management for freshwater reptiles. Biological Conservation, 135, 67-76. https://doi. org/10.1016/j.biocon.2006.09.019

Rothermel, B. B. (2004). Migratory success of juveniles: A potential constraint on connectivity for pond-breeding amphibians. Ecological Applications, 14, 1535-1546. https://doi.org/10.1890/03-5206

Sánchez, E., Colmenarejo, M. F., Vicente, J., Rubio, A., García, M. G., Travieso, L., et al. (2007). Use of the water quality index and dissolved oxygen deficit as simple indicators of watersheds pollution. Ecological Indicators, 7, 315-328. https://doi.org/10.1016/j. ecolind.2006.02.005

Schaldach, R., Alcamo, J., Koch, J., Kölking, C., Lapola, D. M., Schüngel, J., \& Priess, J. A. (2011). An integrated approach to modelling land-use change on continental and global scales. Environmental Modelling \& Software, 26, 1041-1051. https://doi.org/10.1016/j.envsoft.2011.02.013 
Schneider, D. C. (2001). The rise of the concept of scale in ecology: The concept of scale is evolving from verbal expression to quantitative expression. BioScience, 51, 545-553. https://doi.org/10.1641/0006-356 8(2001)051[0545:trotco]2.0.co;2

Semlitsch, R. D. (2002). Critical elements for biologically based recovery plans of aquatic-breeding amphibians. Conservation Biology, 16, 619-629. https://doi.org/10.1046/j.1523-1739.2002.00512.x

Semlitsch, R. D., \& Bodie, J. R. (1998). Are small, isolated wetlands expendable? Conservation Biology, 12, 1129-1133. https://doi. org/10.1046/j.1523-1739.1998.98166.x

Semlitsch, R. D., \& Bodie, J. R. (2003). Biological criteria for buffer zones around wetlands and riparian habitats for amphibians and reptiles. Conservation Biology, 17, 1219-1228. https://doi. org/10.1046/j.1523-1739.2003.02177.x

Simon, J. A., Snodgrass, J. W., Casey, R. E., \& Sparling, D. W. (2008). Spatial correlates of amphibian use of constructed wetlands in an urban landscape. Landscape Ecology, 24, 361-373.

Sinsch, U. (2014). Movement ecology of amphibians: From individual migratory behaviour to spatially structured populations in heterogeneous landscapes. Canadian Journal of Zoology, 92, 491-502. https:// doi.org/10.1139/cjz-2013-0028

Sinsch, U., \& Kirst, C. (2016). Homeward orientation of displaced newts (Triturus cristatus, Lissotriton vulgaris) is restricted to the range of routine movements. Ethology Ecology \& Evolution, 28, 312-328. https:// doi.org/10.1080/03949370.2015.1059893

Skelly, D. K. (2013). Distributions of pond-breeding anurans: An overview of mechanisms. Israel Journal of Zoology, 47, 313-332.

Smith, M., \& Green, D. (2005). Dispersal and the metapopulation paradigm in amphibian ecology and conservation: Are all amphibian populations metapopulations? Ecography, 28, 110-128. https://doi. org/10.1111/j.0906-7590.2005.04042.x

Stauffer, D., \& Aharony, A. (1992). Introduction to percolation theory. Michigan: Taylor \& Francis.

Stevens, V. M., Verkenne, C., Vandewoestijne, S., Wesselingh, R. A., \& Baguette, M. (2006). Gene flow and functional connectivity in the natterjack toad. Molecular Ecology, 15, 2333-2344. https://doi. org/10.1111/j.1365-294x.2006.02936.x

Sztatecsny, M., \& Schabetsberger, R. (2005). Into thin air: Vertical migration, body condition, and quality of terrestrial habitats of alpine common toads, Bufo bufo. Canadian Journal of Zoology, 83, 788-796. https://doi.org/10.1139/z05-071

Taylor, P. D., Fahrig, L., Henein, K., \& Merriam, G. (1993). Connectivity is a vital element of landscape structure. Oikos, 68, 571-573. https://doi. org $/ 10.2307 / 3544927$

Tischendorf, L., \& Fahrig, L. (2000). On the usage and measurement of landscape connectivity. Oikos, 90, 7-19. https://doi. org/10.1034/j.1600-0706.2000.900102.x

Trenham, P., Koenig, W., Mossman, M., Stark, S., \& Jagger, L. (2003). Regional dynamics of wetland-breeding frogs and toads: Turnover and synchrony. Ecological Applications, 13, 1522-1532. https://doi. org/10.1890/02-5206
Uezu, A., Metzger, J. P., \& Vielliard, J. M. E. (2005). Effects of structural and functional connectivity and patch size on the abundance of seven Atlantic Forest bird species. Biological Conservation, 123, 507519. https://doi.org/10.1016/j.biocon.2005.01.001

Van Buskirk, J. (2005). Local and landscape influence on amphibian occurrence and abundance. Ecology, 86, 1936-1947. https://doi. org/10.1890/04-1237

Van Buskirk, J. (2012). Permeability of the landscape matrix between amphibian breeding sites. Ecology and Evolution, 2, 3160-3167. https:// doi.org/10.1002/ece3.424

Vos, C. C., Goedhart, P. W., Lammertsma, D. R., \& Spitzen-Van der Sluijs, A. M. (2007). Matrix permeability of agricultural landscapes: An analysis of movements of the common frog (Rana temporaria). The Herpetological Journal, 17, 174-182.

Werner, E. E., Davis, C. J., Skelly, D. K., Relyea, R. A., Benard, M. F., \& McCauley, S. J. (2014). Cross-scale interactions and the distributionabundance relationship. PLoS ONE, 9, e97387. https://doi. org/10.1371/journal.pone.0097387

Werner, E. E., Yurewicz, K. L., Skelly, D. K., \& Relyea, R.A. (2007). Turnover in an amphibian metacommunity: The role of local and regional factors. Oikos, 116, 1713-1725. https://doi.org/10.1111/j.0030-1299.2007.16039.x

Wu, J., \& Li, H. (2006). Concepts of scale and scaling. In J. Wu, K. B. Jones, H. Li, \& O. L. Loucks (Eds.), Scaling and uncertainty analysis in ecology (pp. 3-15). Dordrecht, the Netherlands: Springer Science \& Business Media. https://doi.org/10.1007/1-4020-4663-4

Zanini, F., Klingemann, A., Schlaepfer, R., \& Schmidt, B. R. (2008). Landscape effects on anuran pond occupancy in an agricultural countryside: Barrierbased buffers predict distributions better than circular buffers. Canadian Journal of Zoology, 86, 692-699. https://doi.org/10.1139/z08-048

Zetterberg, A., Mörtberg, U. M., \& Balfors, B. (2010). Making graph theory operational for landscape ecological assessments, planning, and design. Landscape and Urban Planning, 95, 181-191. https://doi. org/10.1016/j.landurbplan.2010.01.002

\section{SUPPORTING INFORMATION}

Additional supporting information may be found online in the Supporting Information section at the end of the article. 